\title{
Organic nanoparticulate photochromes
}

\author{
Tivadar Feczkó ${ }^{\mathrm{a}^{*}}$, Bojana Voncina ${ }^{\mathrm{b}}$
}

${ }^{a}$ Institute of Materials and Environmental Chemistry, Research Center for Natural Sciences, Hungarian Academy of Sciences, Pusztaszeri u. 59-67., H-1025, Budapest, Hungary

${ }^{\mathrm{b}}$ Institute of Engineering Materials and Design, Faculty of Mechanical Engineering, University of Maribor, Smetanova Ulica 17, SI-2000 Maribor, Slovenia

*Address correspondence to this author at the Research Institute of Chemical and Process Engineering, Faculty of Information Technology, University of Pannonia, Egyetem u. 10., H-8200, Veszprém, Hungary, tel.: +36-88623508, fax: +36-88-624038; e-mail: tivadar.feczko@gmail.com.

\begin{abstract}
Photochromic organic dyes can be widely used in materials for optically rewritable data storage, photonic switches, memories, sensors, or actuators. In recent years photochromic materials based on nanoparticles became particularly focused, since they can be dispersed in colloidal aqueous suspensions or incorporated in thin films, avoiding problems of light scattering or shallow light penetration in bulk materials. Spiropyrans, spirooxazines and diarylethenes were by far the most researched photochromes in nanoparticulate systems. Great effort was made to investigate photochromic dyes incorporated into organic nanoparticles via self-assembly strategies, covalent linkage or dispersion of the molecular species in polymers (doping). Nanoparticles composed of solely photochromic dyes were prepared by laser ablation and reprecipitation techniques. Photochromic dyes were microencapsulated by self-assembly, soap free-, emulsion/microemulsion/miniemulsion or free radical(co)polymerization. Sol-gel processing from silane precursors to poly(organo)siloxane matrix is a common method to synthesize doped or core-shell photochromic organogels. Coloured forms of some photochromes display fluorescence; however, a more effective strategy for fluorescence modulation with photochromic molecules is integrating them, covalently or noncovalently, with a separate fluorophore in the same nanoparticles. These photoresponsive nanoparticles may find applications particularly in biological fields such as cell labelling and bioimaging. The purpose of this review is to summarize the preparation methods of organic nanoparticles containing photochromic dyes and to investigate their typical properties derived from their nanoparticulate character.
\end{abstract}

Keywords: photochromic nanoparticle, laser ablation, reprecipitation, polymerization, doping, fluorescence

\section{INTRODUCTION}

Photochromism is a reversible structural and colour change of a species triggered in one or both directions by electromagnetic radiation [1]. The shift of optical absorption, due to change in molecular structure or conformation results in colourization, while the coloured product decolourizes after a structure rearrangement in the back (generally thermal) reaction. The reversible transformations of photochromic compounds are usually based on ring opening/closing steps, cis/trans isomerizations, proton transfer, electron transfer or cycloadditions [2]. Like other stimuli responsive materials (e.g. heat and $\mathrm{pH}$-sensitive materials), photochromic devices are responsive to an external stimulus, in this case, light. Light is the most attractive stimulus due to the fact that its wavelength, intensity and focus can be tuned.

Photochromic materials have been investigated extensively during the past few decades because of optical responses and nonlinear optical, electronic and magnetic properties [3]. Photochromic materials have a high potential for applications to ophthalmic lenses [4,5], communication systems [6], security printing [7], optically rewritable data storage [8] and memory devices [9-11], optical switching [12], chemical sensing [13], shapememory systems [14], as recording and switching sensors [15], and also for microstructuring and patterning surfaces [16]. Therefore, photosensitive, nanoscaled materials such as nanoparticles, nanofibers, and nanofilms are utilized not only in nanotechnologies but also in biomedical fields, i.e. biomaterial sensors [17], analysis of biological dynamics, and live cell imaging [18-20].

The electronic and optical properties of organic compounds are fundamentally different from those of semiconductors and metals due to their weak intermolecular interactions and the small radius of the Frenkel exciton [21]. Photochromic compounds are usually classified into two types [22]: thermally unstable- (T-type) and thermally stable one (P-type). T-type involves the following main photochromes such as spiropyrans (SP) (Scheme 1), spirooxazines (SO) (Scheme 2), azobenzenes (Scheme 3). They exhibit full or partial thermal bleaching processes, which are generally applied in optical filters, ophthalmic lenses, smart windows and holographic displays. The spiro-compounds, both spirooxazines and spiropyrans, have been standing in the focus of attention as they have good colouration properties and spirooxazines also display good fatigue resistance $[1,23]$. Colourless spiropyrans/spirooxazines undergo photo-induced ring-opening reactions under ultraviolet 
irradiation to generate their isomeric merocyanine (MC) forms (Scheme 1), which have strong solvatochromic visible absorption bands in the range of 500- $600 \mathrm{~nm}$. This band arises from the extended $\pi$-conjugation that develops between the indolene and the pyran rings following the rupture of the C (spiro)-O bond [24].<smiles>CN1c2ccccc2C(C)(C)C12C=Cc1cc([N+](=O)[O-])ccc1O2</smiles>

Spiropyran

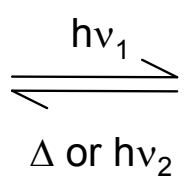

$\Delta$ or $h v_{2}$

Scheme 1. Reversible ring-opening/closing photochromic reaction of spiropyran/merocyanine<smiles>CN1c2ccccc2C(C)(C)C12C=Nc1c(ccc3ccccc13)O2</smiles>

Spirooxazine

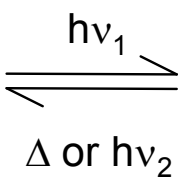

$\Delta$ or hv 2<smiles>CO[N+](=O)c1ccc([O-])c(/C=C/C2=[N+](C(C)C)c3ccccc3C2(C)C)c1</smiles>

Scheme 2. Reversible ring-opening/closing photochromic reaction of spirooxazine/ merocyanine<smiles>[R]c1ccc(/N=N/c2cccc([R2])c2)cc1</smiles><smiles>[R]c1ccc(/N=N/c2ccc([R2])cc2)cc1</smiles>

Scheme 3. Reversible photoisomerization of azobenzene

The thermally stable type (P-type), including the most important species, those possessing the hexatriene framework provided by 1,2-diarylethene, especially 1,2-dithienylethene and 1,2-dibenzothienylethene has attracted special attention (Scheme 4). Their main advantages are high efficiency of ring-closure and ringopening photoisomerization, sufficient thermal stability of both forms and very high fatigue resistance [25]. Diarylethenes have two conformations in solution, parallel and antiparallel, and they interconvert. Photocyclization takes place only from the antiparallel conformation [26]. They may find sustainable applications, such as optical memory media, switching devices, light-driven actuators [27] and also as biological applications such as the development of biomaterial sensors, analysis of biological dynamics, and live cell imaging [18] due to their remarkably thermal stability and photofatigue resistance. 


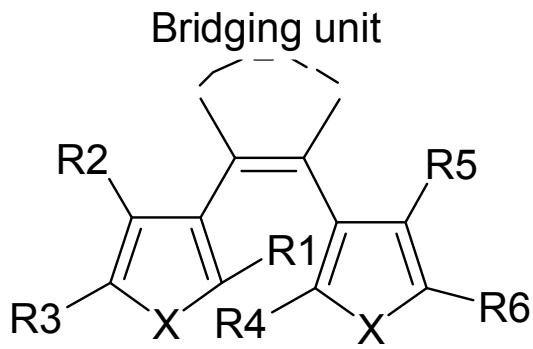

Open-ring isomer

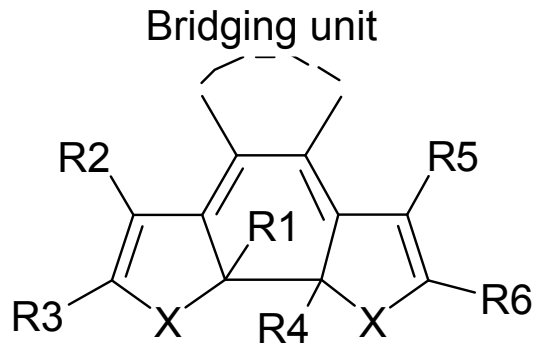

Closed-ring isomer

Scheme 4. Reversible ring-closing/opening photochromic reaction of diarylethenes

In order to achieve solid state photochromic applications, the active molecules are embedded in a solid matrix, since photochromic species in their pure crystalline form are usually inactive [1]. In addition, conventional photoresponsible molecular devices tend to aggregate in aqueous media which affects their optical properties. The arrangement of molecules in aggregates is generally divided into $\mathrm{H}$ and $\mathrm{J}$ types [28]. Formation of $\mathrm{H}-$ aggregates is characterized by blue-shifted absorption bands and relatively low fluorescence efficiency in comparison with those of isolated molecules. A J-aggregate possesses an absorption band that shifts to a longer wavelength (bathochromic shift). In J-aggregates the optical properties of the organic dyes are much more advantageous for various technological applications such as spectral sensitization, optical storage and nonlinear optics than in H-aggregates [29]. Molecular aggregation in polymer is a common phenomenon observed in some photochromic systems [30]. Some optical properties, such as absorption and emission spectra, photorefractive effect, non-linear optical properties, and birefringence can be affected by the aggregation. Upon irradiation with light, the aggregation morphology and optical properties may change reversibly due to photo-induced isomerization.

Photochromic dyes usually lack the essential biocompatibility for applications in the fields of biotechnology [31]. Hence, the development of photoresponsible nanoparticles opens new possibilities for individually addressable nanoscale devices. In biological applications the photoreversible fluorescent nanoparticles can be used to selectively highlight cells or proteins $[24,32]$. Conjugated polymer nanoparticles offer advantages relative to small molecule fluorophores including their good photostability and brightness [33]. The nano-sized dimension provides facilitated permeation and absorption into biological tissues as well as an enhanced surface area. [34] Over the last decade, micro- and nano-sized capsules, composed of organic or inorganic materials or both, were developed owing to the wide range of their potential applications. Their main advantages are controllable permeability into the inner cavity, low density and large specific area [34]. Nanoparticles can be dispersed in colloidal aqueous solutions or incorporated in thin-layer matrices, avoiding light scattering or shallow light penetration in bulk materials, and providing optically suitable media [35].

Classical strategies for photochrome incorporation into organic media include the dispersion of the molecular species (doping) in polymers [36,37] or in organogels [38,39]. A different route of photochromic dye encapsulation is their polymerization reaction with suitable polymers in emulsion polymerization [24,40], microemulsion copolymerization [21] or miniemulsion polymerization [41]. A very important class of photochromic dye containing nanoparticles is hybrid inorganic-organic composites by attaching photochromes on the surface of magnetic [42,43], silver [44], gold [45-49], silica [50-53] and semiconductive, e.g. CdS [54] or $\mathrm{CdSe} / \mathrm{ZnS}$ [55] nanoparticles. Less frequent applications of photochromic dyes with inorganic carriers are layered intercalation compounds [56,57].

Inorganic nanocarriers for photochromic dyes have already been thoroughly reviewed by Klajn et al. [58]. They evaluated materials which comprise nanoparticles supplied with self-assembled monolayer of molecular and supramolecular switches. Ariga et al. 2012 [59] studied mesoporous inorganic and organic carriers for various purposes. Katsonis et al. [60] investigated monolayers of bistable photochromic switches, too; however, they also focused on inorganic nanoparticles, especially on gold. Such et al. [23] extensively studied the inclusion of spiro compounds into polymer matrices with regard to polarity, rigidity, or temperature influence on photochromism; colouration and decolouration behaviours; solvatochromism; the mechanism of fatigue; and unusual synthetic approaches. Every important factor influencing photochromism in polymer matrices, mainly in films, is discussed in their review. Nevertheless, most of the research on photochromes encapsulated in organic nano-sized media has been achieved since that exhaustive work [23]. Hence, our purpose is to fill the gap of reviewing photochromic dyes containing organic nanoparticles, and focus on those properties that are typical of photochromic nanoparticles and are in close relation with their nanoparticulate character. Thus, we did not consider those photochromic features which were also observed in different media such as in solution or film, separately or in a complexed form, since these have already been comprehensively discussed in previous and recent valuable works $[1,18,23,61,62]$. Both organic and inorganic matrix can possess advantageous properties; 
the appropriateness of a material strongly depends on the pending application. Nevertheless, the synthetic methodology of an organic matrix in some cases might be simpler than that of quantum dots [63]. Moreover, entrapment of organic photochromes can be more efficient by organic materials than by inorganic carriers, and generally leakage of the dye is less probable from an organic system.

Our review summarizes the main methods of preparation of organic nanoparticulate photochromes, and we separately discuss those nanosystems which show fluorescence modulation beside the photochromic property.

\section{PREPARATION METHODS}

By laser ablation, reprecipitation and self-organization pure photochromic nanoparticles can be synthesized (Table 1). Organic polymeric photochromic nanocapsules have been widely formulated by different polymerization techniques such as polymerization induced self-assembly, free radical polymerization, emulsion/miniemulsion/microemulsion polymerization or soap-free emulsion polymerization (Table 2). Doping is another convenient way of nanoparticulate photochrome preparation, whilst organogels represent a special class of nanocarriers (Table 3).

\subsection{Pure photochromic nanoparticles \\ Laser ablation}

Laser ablation is a reliable topdown approach for nanoparticle fabrication. Although it is relatively energy consuming, it does not demand organic solvents, and issues in aqueous colloidal suspensions of insoluble molecules with desirable optical properties.

Microcrystalline powder suspensions of diarylethenes such as (1,2-bis[4'-methyl-2'-(2', pyridyl)thiazolyl]perfluorocyclopentene [64] and 1,2-bis[5'-ethoxy-2'-(2'-pyridyl) thiazolyl) perfluorocyclopentene] [3] were prepared by laser ablation in a water-sodium dodecylsulfate and waterdodecyltrimethylammonium bromide media, respectively. The resulting suspension was mostly composed of monodisperse nanoparticles with $25 \pm 10 \mathrm{~nm}$ diameters. The photochromic reaction occurred efficiently at the very beginning of the laser shots, leading to a photostationary state within $3 \mathrm{~min}$, whereas the ablation process was still effective even after $16 \mathrm{~min}$. In the initial time the laser ablation treated mainly the opened form microcrystals. Whilst during most of the ablation time, the materials, fragmented into smaller particles, were composed of a mixture of opened and closed molecules, hence absorption bands appeared both in the UV and visible regions. While light scattering diminished, the absorption bands of closed form increased. Two processes took place at the same time, but the photochromic reaction was significantly faster than the laser-induced fragmentation. The nanomaterials formed by laser ablation behave as an intermediate between the solution and solid state [3,64]. Because of their small sizes and large surface-to-volume ratio, the molecular arrangement and the crystal lattice of nanoparticles is less rigid than in the bulk crystal. Nevertheless, their crystal packing determined by X-ray diffraction showed that the absorption transition moments of the molecules were lined up along the same direction [35]. That is, the polarization angles of high scattering intensities corresponded to the alignment direction. Such characteristic was an evidence of the (at least partial) crystalline character of the nanoparticles. The suspensions were stable, without noticeable aggregation for a few days [3,64], and also in a study for six months [35]. Fig. (1) shows the preparation and microscopy image of 1,2-bis(5'-ethoxy-2'-(2''pyridyl) thiazolyl) perfluorocyclopentene (1) nanoparticles in aqueous solution of dodecyltrimethylammonium bromide (DTAB) by the $355 \mathrm{~nm}$ beam of a nanosecond Nd:YAG laser [35]. The initial colourless opaque suspension was gradually transformed to a purple transparent colloidal solution. 


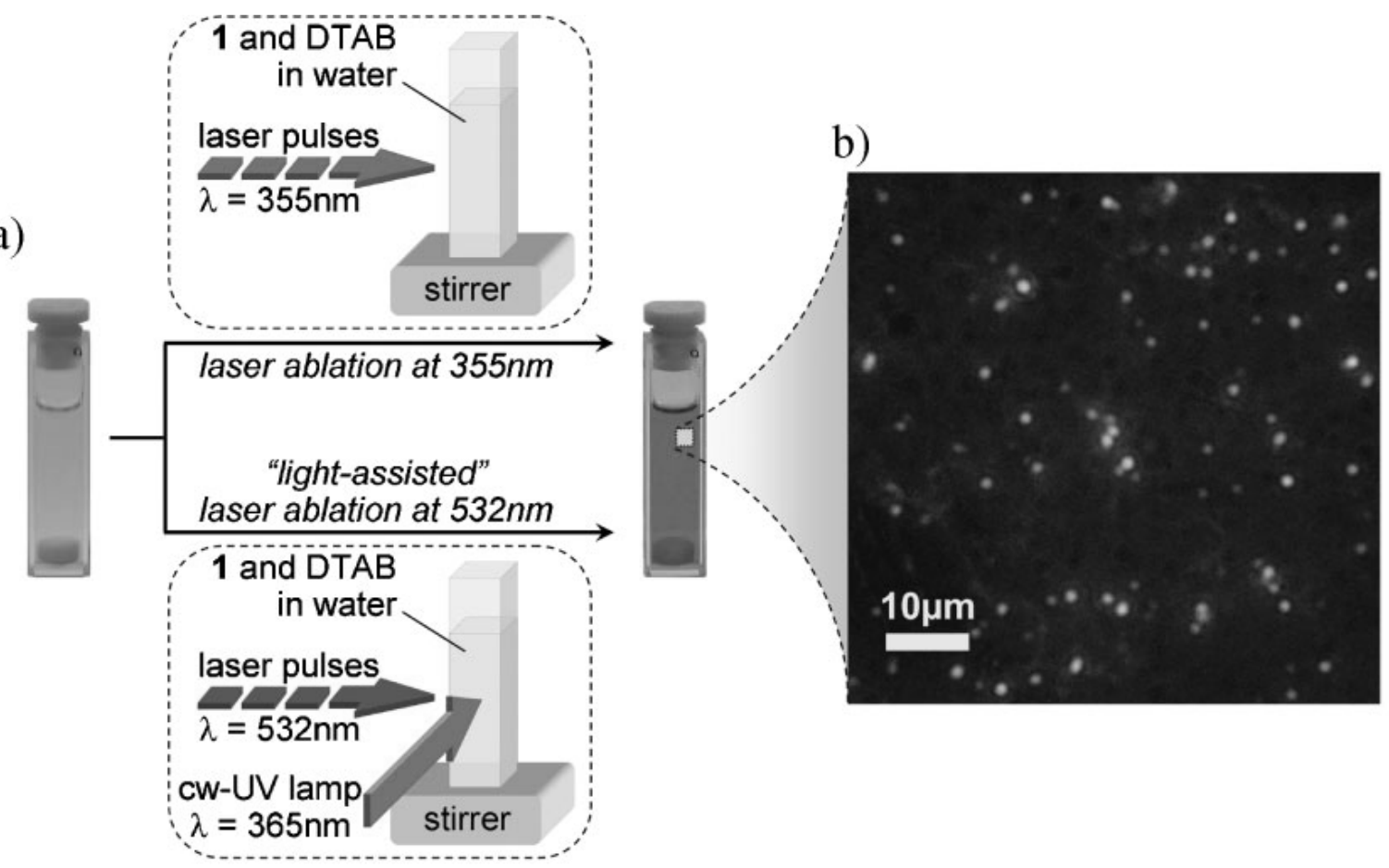

Fig. (1). Laser ablation of 1 at 355 and $532 \mathrm{~nm}$. a) Schematic view of the two different experimental conditions for laser ablation. Pictures show the cuvette before (opaque suspension) and after (clear purple colloidal solution) laser ablation. b) Dark-field microscopy image of nanoparticles (sample obtained by spin-casting the colloidal solution - filtered at $\varnothing=220 \mathrm{~nm}$ - on a glass cover slip) (reproduced with permission from [35]).

One dimensional cis-1,2-dicyano-1,2-bis(2,4,5-trimethyl-3-thieny1)ethene nanorods and nanowires with width and length ranging from $60-120 \mathrm{~nm}$ and $400-1200 \mathrm{~nm}$, respectively were prepared by light inducing. They were reversibly redispersed and showed fast, fatigue resistant optical switching [65]. Nanorods of an anil (N-(3,5-ditertbutylsalicylidene)-4-aminopyridine) fabricated by a laser ablation method demonstrated reversible and fatigue-resistant optical switching and second-harmonic generation activity [3]. Photochromism and thermochromism of anils (salicylideneanilines, salicylidene-aminopyridines and related Schiff bases) is due to their ability to undergo proton tautomerism, defined as the reversible excited state proton transfer between the enol(-imine) and the keto(-amine) form caused by electromagnetic radiation or heat, respectively [66] (Scheme 5). The H-transfer can occur either in the ground (thermochromism) or the excited electronic state (photochromism). Their fast kinetics is particularly suitable for rapid switching applications. The width and height of the nanorods typically ranged from $70-200 \mathrm{~nm}$. The rate of thermal back reaction of nanoparticle dispersions followed a double exponential kinetics. The fast and slow components of the decay were attributed to the cis-keto- and trans-keto form, respectively. The different relaxation behaviour of the molecules at the surface and bulk of the nanocrystals may lead to the biexponential decay. Under sustained laser irradiation, the solution became turbid and the absorption bands decreased concomitantly, indicating a possible degradation of the compound. Switching could be repeated several times on the same particle indicating the ability of such materials to act as photoswitchable nano-objects [35].

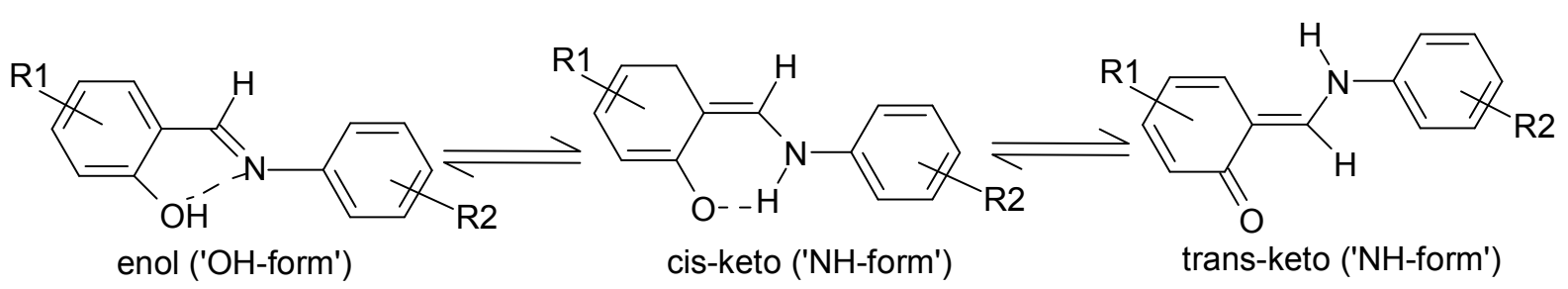

Scheme 5. Reversible photochromic and thermochromic reactions in anils

\section{Reprecipitation}

Nanoparticles of a diarylethene derivative (1,2-bis(2-methyl-5-(p-hydroxyphenyl) thien-2yl)perfluorocyclopentene) were prepared by a reprecipitation method [67,68]. Nanocrystals of 1,2-bis(2,4dimethyl-5-phenyl-3-thienyl)perfluorocyclopentene were formed by the microwave-assisted reprecipitation [67]. 
During aggregation, the polar hydroxy groups get to the surface of the aggregate, whilst the hydrophobic perfluorocyclopentene parts remain inside the aggregate. The induced negative zeta potential in nanoparticles generates steric repulsions among the aggregates. In addition, the perfluorocyclopentene parts deform locally. The intramolecular deformation, intermolecular steric repulsions, and hydrogen bonding effects twist molecular conformation and restrict molecular mobility. As a result, the disrotatory of thiophen rings in the photocyclization reaction is limited. On the other hand, the restricted molecular mobility and the twisted conformation are advantageous to the ring-opening reaction. The nanoparticles are held together by hydrogen bonding and hydrophobic effects. Electrostatic repulsion prevents coalescence of nanoparticles in water. The experimental results showed that temperature greatly influenced the process of nanoparticle formation. The mean mass diameter of aggregation decreased with the increase of temperature from 170-230 nm to 60-100 nm [68]. Tagawa et al. [67] controlled aggregate size between $40-250 \mathrm{~nm}$ by changing the concentration of the injected solution, and thus, the viscosity of good solvent. The UV-Vis spectra of diarylethene nanoparticles were significantly different compared to that of the corresponding diarylethene solution. The peak width was broadened and its shape was asymmetric. Although the absorption spectra of the open ring forms changed little, the absorption maximum peaks of the closed-ring forms showed a great hypsochromic shift $(>20 \mathrm{~nm})$. The absorption maximum peaks of the closed-ring form were blue-shifted. The blue shift was explained by Haggregates formation, which was consistent with the decreased fluorescence efficiency of the open-ring form. Spectrokinetic examination showed that photochromic transformations were strongly affected by molecular aggregation. The decrease of photocyclization activity was mainly attributed to the intra- and intermolecular effects exerted by aggregation. The diarylethene aggregates exhibited different photochromic behaviors from the isolated molecules. The photo-cyclization in nanoparticles was greatly depressed by the restricted molecular mobility and twisted conformations.

SO (6'-hydroxy-5-methoxy-1,3,3-trimethyl-spiro[indoline-2,2'-naphtho[1,2-b]-1,4,2-oxazine]) nanoparticles had an average diameter of $150 \mathrm{~nm}$ and $220 \mathrm{~nm}$, respectively, prepared by the reprecipitation method [69]. The absorption band of MC nanoparticles gradually widened and the maximum absorption wavelength showed a slight bathochromic shift compared to the monomer of MC with increasing the particle size. The tailing edge of the spectra at long wavelength became more pronounced for the larger particles than for the smaller ones, due to the Mie scattering effect. The decolouration reaction is a space-demanding process, because the two ring systems transfer from a coplanar to perpendicular configuration. The fast and quasi-molecular dispersion behaviour was contributed by the molecules on the surface, while the much slower one was attributed to the inside ones. Upon aggregation the intermolecular interactions increase owing to the more densely packed molecules. As a result, the decolouration process became slower with increased particle size. Reprecipitated nanoparticles possessed 600 times higher decaying lifetime for $\mathrm{MC}$ nanoparticles related to the dispersed molecules.

Fluorescence modulation was accomplished by composite nanoparticles of $70-100 \mathrm{~nm}$, based on photochromic SO (5-methoxy-1,3,3-trimethyl-9'-hydroxyspiroindolinenaphthoxazine), fluorescent 4-(dicyanomethylene)-2methyl-6-(p-dimethyl-aminostyryl)-4H-pyran dye and emissive assistant 1,3-bis(pyrene)propane molecules reprecipitated [70]. (Z)-2,3-bis(4'-methyl-[1,1'-biphenyl]-4-yl)-acrylonitrile and 2,3-bis(4'-(diphenylamino)[1,1'-biphenyl]- 4-yl)fumaronitrile fluorophores and a photochromic diarylethene, 3,3'-(perfluorocyclopent-1ene-1,2-diyl)bis(2-methyl-5-phenylthiophene) were reprecipitated, and demonstrated highly efficient stimulusresponsive fluorescence colour tuning by combining the FRET with photochromic switching [71].

\section{Self-organization}

Azide groups, diazo groups, and cinnamate groups are widely used as photochromic groups for photosensitivity [72]. Cinnamic acid and its derivates exist in plant cell walls as an intermediate metabolite in the biosynthetic pathway of lignin and other biological materials and show several photoreactions such as [2+2] cycloaddition and trans/cis isomerization, which lead to the transformation of the photoactive yellow protein in photosynthetic bacteria. Bio-based poly(3,4-dihydroxycinnamic acid-co-4-hydroxycinnamic acid) nanoparticles were selforganized by mixing two homogeneous solutions in dimethylformamide and trifluoroacetic acid [72]. Their diameter was approximately $860 \mathrm{~nm}$ after dispersion in tetrahydrofuran, which decreased to about one-half (420 $\mathrm{nm}$ ) during UV irradiation over $280 \mathrm{~nm}$ and rapidly recovered to $620 \mathrm{~nm}$ upon subsequent irradiation at $254 \mathrm{~nm}$. The size change phenomenon corresponded to [2+2] cycloaddition formation and cleavage of the cinnamate groups (Scheme 6). The reason for this significant size change was that all units of the copolymer contained photochromic groups. Furthermore, these photo-cross-linked bio-based nanoparticles showed various size change behaviours during hydrolytic degradation depending on the degree of cross-linking. The diameter decreased with increasing solvent polarity due to different swelling capabilities of the nanoparticles. UV induced size change of the nanoparticles was observed also in dioxane and dimethylsulfoxide. The magnitude of the size change was independent of the polarity. 

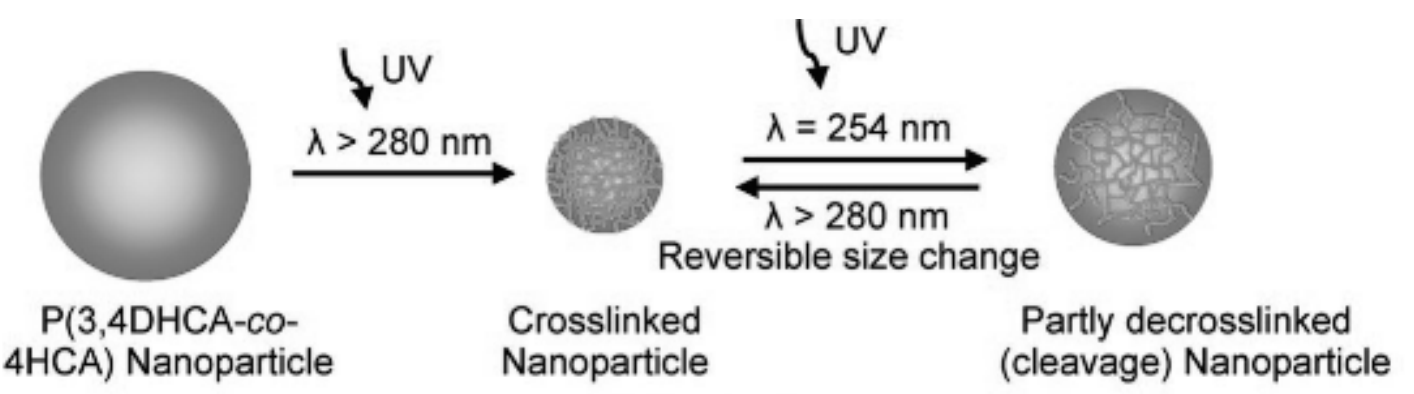

: crosslinking bond
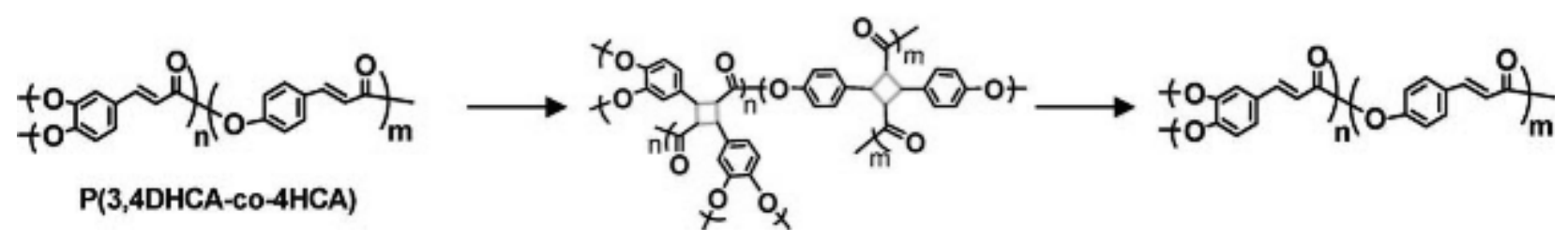

Scheme 6. Schematic representation of size change behavior of $\mathrm{P}(3,4 \mathrm{DHCA}-\mathrm{co}-4 \mathrm{HCA})$ nanoparticles with UV irradiation; chemical structure of UV-Induced [2 + 2] cycloaddition formation (cross-linking) and deformation (cleavage) (reproduced with permission from [72]).

The photocontrollable J-aggregation of diarylethene Zn-phthalocyanine hybrid (T-ZnPc), composed of one zinc phthalocyanine $(\mathrm{ZnPc})$ and four diarylethene units, was achieved and investigated [73]. T-ZnPc reversibly formed strong J-aggregates (100-250 nm) upon UV light illumination as a result of the pronounced enhancement in the molecular planarity accompanying the ring-closure reaction of its diarylethene units. The thermal stability of the closed-ring diarylethene isomers in molecularly dispersed T-ZnPc was much poorer than that in aggregates. As long as the aggregates were broken, they converted to corresponding open-ring form instantly, which may explain that photochromism of the hybrid was not observed in coordinating solvents such as tetrahydrofuran or pyridine. 
Table 1 Formulas, additives and size (ranges) (nm) of pure photochromic nanoparticles.

\begin{tabular}{|c|c|c|c|c|}
\hline $\begin{array}{c}\text { Photochrome } \\
\text { type }\end{array}$ & Photochrome & Additive(s) & Size (nm) & Ref. \\
\hline Diarylethene & 1,2-bis[4'-methyl-2'-(2''-pyridyl) thiazolyl]perfluorocyclopentene & - & 25 & [64] \\
\hline Diarylethene & 1,2-bis[5'-ethoxy-2'-(2'-pyridyl) thiazolyl) perfluorocyclopentene] & - & - & [3] \\
\hline Diarylethene & cis-1,2-dicyano-1,2-bis(2,4,5-trimethyl-3-thieny1)ethene & - & $\begin{array}{l}\text { Width: } \\
\text { 60-120 } \\
\text { Length: } \\
\text { 400-1200 }\end{array}$ & {$[65]$} \\
\hline Anil & $\mathrm{N}$-(3,5-di-tertbutylsalicylidene)-4-aminopyridine & - & $70-200$ & [3] \\
\hline Diarylethene & 1,2-bis(2-methyl-5-(p-hydroxyphenyl) thien-2-yl)perfluorocyclopentene & - & $40-250$ & [68] \\
\hline Diarylethene & 1,2-bis(2,4-dimethyl-5-phenyl-3-thienyl)perfluorocyclopentene & - & $\begin{array}{c}170-230 \\
60-100 \\
\end{array}$ & {$[67]$} \\
\hline Spirooxazine & $\begin{array}{l}\text { 6'-hydroxy-5-methoxy-1,3,3-trimethyl-spiro[indoline-2,2'-naphtho[1,2-b]- } \\
\text { 1,4,2-oxazine] }\end{array}$ & - & 150,220 & [69] \\
\hline Spirooxazine & 5-methoxy-1,3,3-trimethyl-9'-hydroxyspiroindolinenaphthoxazine & $\begin{array}{l}\text { 4-(dicyanomethylene)-2-methyl-6-(p-dimethyl- } \\
\text { aminostyryl)-4H-pyran fluorescent dye, } \\
\text { 1,3-bis(pyrene)propane emissive assistant }\end{array}$ & $70-100$ & {$[70]$} \\
\hline Diarylethene & 3,3'-(perfluorocyclopent-1-ene-1,2-diyl)bis(2-methyl-5-phenylthiophene) & $\begin{array}{l}\text { (Z)-2,3-bis(4'-methyl-[1,1'-biphenyl]-4-yl)- } \\
\text { acrylonitrile, 2,3-bis(4'-(diphenylamino)-[1,1'- } \\
\text { biphenyl]- 4-yl)fumaronitrile fluorescent dyes }\end{array}$ & 261 & [71] \\
\hline Cinnamic acid & poly(3,4-dihydroxycinnamic acid-co-4-hydroxycinnamic acid) & - & 860,420 & [72] \\
\hline Diarylethene & diarylethene-Zn-phthalocyanine hybrid & - & $100-250$ & [73] \\
\hline
\end{tabular}




\subsection{Polymerization techniques}

\section{Polymerization induced self-assembly}

Amphiphilic photochromic copolymer consisting of a hydrophilic poly(N-isopropylacrylamide) backbone and hydrophobic dithienylethene (N-(4-(4-(3,3,4,4,5,5-hexafluoro-2-(2-methyl-5-phenylthiophen-3-yl)cyclopent-1enyl)-5-methylthiophen-2-yl)phenyl)acrylamide) was fabricated by self-assembled copolymer nanoparticles in aqueous condition [74]. The photochromic monomer copolymerized with $\mathrm{N}$-isopropylacrylamide by free radical polymerization method and using 1,1'-azobis(cyclohexane-1-carbonitrile) initiator. The nanoparticles had uniform size $(150 \mathrm{~nm}$,) and were highly stable. They reversibly switched between two states with the dual stimuli of light and temperature in an aqueous suspension.

Self-assemble of the dithienylethene, 1,2-bis[2-methyl-5-(4-pyridyl)-3-thienyl]cyclopentene was achieved in tetrahydrofuran solution with 3,4,5-tris(dodecyloxy)benzoic acid after slow injection into water under stirring [75]. The intermolecular hydrogen bond interaction between the carboxylic acid as the donor and the pyridine group with a lone electron pair as an acceptor acted as a driving force for the formation of self-assembled composites.

Vesicles prepared by polymerization induced self-assembly and reorganization displayed stronger fluorescence and excellent photostability due to confinement of conformational flexibility of the polymer chains in aggregates [76]. The photochromic polymeric vesicles composed of the amphiphilic block copolymer, poly(4-vinylpyridineco-methacrylated spiropyran)-b-polystyrene (P(4VP-co-SPMA)-b-PS) were successfully prepared via reversible addition-fragmentation chain transfer (RAFT) dispersion polymerization using the SP, 1'-(2-methacryloxyethyl)3',3'-dimethyl-6-nitro-spiro(2H-1-benzo-pyran-2,2'-indoline) (SPMA) (Fig. (2)). Their average diameter ranged from 200 to $430 \mathrm{~nm}$. Instability of the SP dyes was mainly induced by bimolecular degradative reactions that involve the triplet-excited dye. The P4VP chains containing SP molecules were attached to the PS domain in the wall of vesicles, and the mobility of P4VP chains were restricted, which minimized the bimolecular degradative reactions. The same group [77] synthesized micelles built from photo- and $\mathrm{pH}$-responsive amphiphilic hyperbranched star copolymers, poly(6-O-methacryloyl-1,2,3,4-di-O-isopropylidene-D-galactopyranose)[poly(2(N,N-dimethylaminoethyl)methacrylate)-co-poly(1'-(2-methacryloxyethyl)-3',3'-dimethyl-6-nitro-spiro(2H-1-

benzo-pyran-2,2'-indoline)) $]_{n}$ [HPMAlpGP(PDMAEMA-co-PSPMA) ${ }_{n}$ by the same polymerization method. The forming core-shell micelles with size of $120 \mathrm{~nm}$ possessed HPMAlpGP core and PDMAEMA-co-PSPMA shell. A nitrobenzoxadiazolyl derivative (NBD) fluorescent dye was loaded into the SP containing micelles. Their cytotoxicity was lower than that of $25 \mathrm{kDa}$ polyethyleneimine.

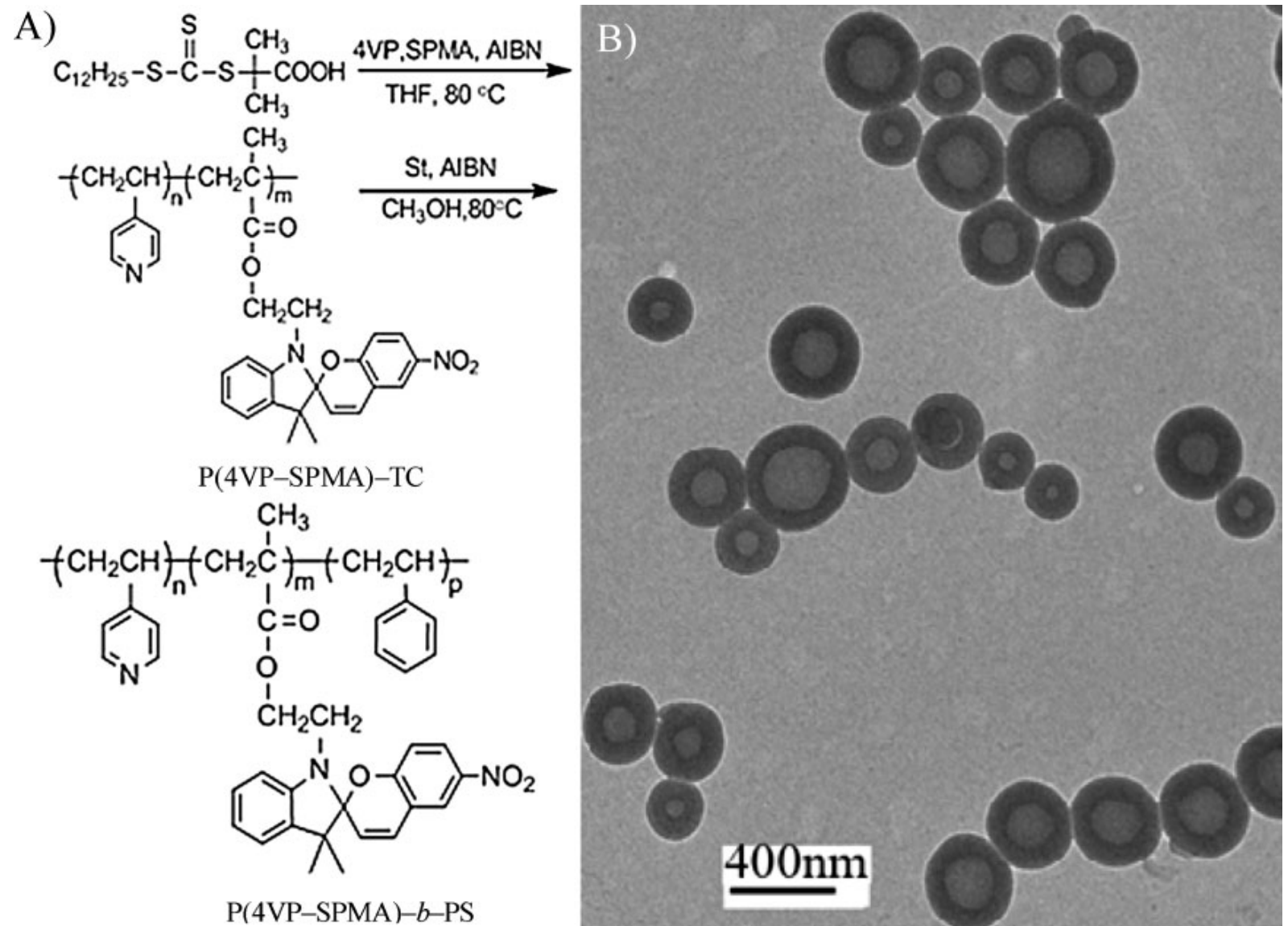


Fig. (2). (A) Synthetic route of functional vesicles via RAFT dispersion polymerization in methanol. (B) TEM image of vesicles formed by RAFT dispersion polymerization of St with feed molar ratio of St/P(4VP-coSPMA)-TC/AIBN $=10$ 000/1/0.1 (concentration of St is $66.2 \mathrm{wt} \%$ ) for $36 \mathrm{~h}$, (reproduced with permission from [76].

\section{Free radical polymerization}

Amphiphilic core-shell nanoparticles polymerized from poly(ethyleneimine) (PEI), methyl methacrylate (MMA), acrylate-linked SP (SPMA), ethylene dimethacrylate (EDMA) using tert-butyl hydroperoxide initiator containing l'-( $\beta$-carboxyethyl)-3',3'-dimethyl-6-nitrospiro[indoline-2',2-chromane] as photochromic dye were prepared in aqueous media [78]. As the copolymer of MMA, SPMA, and EDMA is hydrophobic, it built the core, whereas the biocompatible PEI chains remain hydrophilic; consequently, they constituted the shell of nanoparticles. The hydrophobic core of the nanoparticles contains and protects the SP moieties, whereas the hydrophilic shell allows the nanoparticles to be dispersed in water and forms an interface with the hydrophobic core to accommodate the hydrophobic dyes. The average diameters of the prepared core-shell particles were in the range of 80-130 nm, depending on the PEIs used and the ratio of PEI to MMA. The hydrophobic core diameter was calculated to be $76 \mathrm{~nm}$ of particles having average diameter of $82 \mathrm{~nm}$. As the upper limit of the effective energy transfer distance in this sample is $6.5 \mathrm{~nm}$, the outer sphere of about $6 \mathrm{~nm}$ thickness, which represents about $43 \%$ of the overall volume of the hydrophobic core of the nanoparticle system, serves as the effective area in which the MC form of the SP can quench the fluorescence emission of NBD. In this regard, the preparation of smaller nanoparticles can further increase the ratio of the effective volume in a nanoparticle. A hydrophobic fluorescent dye based on the NBD group was introduced into the nanoparticles to form NBDnanoparticle complexes in water. The photochromic switching time was much longer than that of SP molecules in organic solutions, because of the solid-state environment of the nanoparticles in which configurational switching must overcome energy barriers imposed by the closely packed organic molecules. Photodamage of NBD and SP was observed.

\section{Emulsion polymerization}

The main asset of polymerization methods is that they are much simpler than the covalent chemical synthesis [40, 41]. A SP, (5-(1,3-dihydro-3,3-dimethyl-6-nitrospiro[2H-1-benzopyran-2,2'- (2H)-indole])ethyl acrylate) was incorporated by a modified emulsion polymerization into the hydrophobic cavities/pockets of polymer nanoparticles composed of hydrophilic $N$-isopropylacrylamide shell and styrene core in combination with divinyl benzene as the cross-linker [24]. The nanoparticle size varied between 40 and $400 \mathrm{~nm}$ in diameter. In another work also published by Zhu et al. [40] perylene diimide fluorescent dye was incorporated into the same core-shell nanoparticles together with the SP. In this system the photoexcited acceptor is also fluorescent emissive, so that the energy of the emitted photon was dependent upon the isomeric state of the second photoswitchable chromophore (SP or MC). The nanoparticles were spherical with mean diameters varying from 50 to $110 \mathrm{~nm}$ depending on the ratio of monomers. They also had negatively charged carboxyl functional groups on their surfaces; hence, they could be easily dispersed in water and were stable in many biological buffers and extracellular fluids both above and below their lower critical solution temperature (LCST).

Fatigue caused by photodegradation of the SP under UV-irradiation is commonly observed. However, the polymer nanoparticle displays better reversibility when compared to other environments, including SP molecules in solution or covalently attached to nanocrystal surfaces. One factor contributing to this stability may be that incorporation minimizes bimolecular degradative reactions that involve the triplet-excited dye $[24,40]$. On the other hand, the solid-state environment of the nanoparticles results in a slower switching speed than in solution, since configurational switching must overcome significantly higher energetic barriers imposed by the closely packed organic molecules in solid phase. Restricted conformational flexibility clear rate differences between forward and backward photoisomerization.

\section{Miniemulsion polymerization}

Differently from emulsion polymerization, in miniemulsion polymerization a co-stabilizer (usually highly waterinsoluble hydrophobes such as long chain alkanes) is added to the monomer, and the initial reaction mixture is subjected to very high shear (e.g. by ultrasonicator or high pressure homogenizer;), creating monomer droplets of 50-500 nm [79]. Each of the droplets can be regarded as an individual batch reactor; a variety of substances can be introduced into individual miniemulsions and then polymerized to obtain colloidal particles [80]. In the mechanism of miniemulsion polymerization, once the chromophore molecules are included in the monomer droplet, they can remain inside the droplet till the completion of polymerization [81]. Polymerization was triggered in an aqueous miniemulsion obtained by mixing styrene monomer, photochrome, and azobisisobutyronitrile or azo-polyethylene glycol initiator and added into a surfactant containing aqueous solution [79]. A SP (1',3'-Dihydro-1',3', 3'-trimethyl-6-nitrospiro[2H-1-benzopyran-2,2'-(2H)-indole]) and various diarylethenes (cis-1,2-dicyano-1,2-bis(2,4,5)-trimethyl(3-thienyl)ethene, 1,2-bis(2- 
methylbenzo[b]thiophene-3-yl)hexafluorocyclopentene, 1,2-dicyano-1,2-bis(2-methylbenzo[b]thiophene-3yl)ethene, 1-(6'-acetyl-2'-methylbenzo[b]thiophen-3'-yl)-2-(2''-methylbenzo-[b]thiophen-3''yl)hexafluorocyclopentene, $\quad 1$-[6'-(methacryloxyethyloxycarbonyl)-2'-methylbenzo[b]thiophen-3'-yl]2,(2'methylbenzo[b]-thiophen-3"'-yl)hexafluorocyclopentene), respectively, were microencapsulated with this method. The miniemulsion was heated and the initiator thermally decomposed; the monomer droplets were nucleated. Photochromes were used as hydrophobe to stabilize the styrene droplets against diffusional degradation (Ostwald ripening). The morphology of the prepared nanocapsules showed core/shell structure with average diameter of 50-150 $\mathrm{nm}$. Similar stable nanocapsule dispersions were prepared by using different diarylethenes, though the spirobenzopyran derivative containing nanocapsule suspension was unstable. Nonsymmetric capsules were obtained in the system prepared by using azo-polyethylene glycol, indicating that its polyethylene glycol unit could destabilize partly the emulsion. Symmetric nanocapsules of diarylethene could be formed in the presence of the non-ionic initiator, azobisisobutyronitrile.

In a similar system, although comprising methyl methacrylate and 2-hydroxyethyl methacrylate monomers and a SP (1-( $\beta$-carboxyethyl)-3', 3'-dimethyl-6 -nitrospiro (indoline-2',2[2H-1] benzopyran)), the average diameter of the nanoparticles was between $30 \mathrm{~nm}$ to $60 \mathrm{~nm}$ [81]. The nanoparticle dispersions exhibited enhanced photoreversibility, photostability and relatively fast photo-responsive property compared to the same species in solution. The absorption behaviour for the dispersion is similar to that of the SP-linked methacrylate monomer, except that the light scattering effect of nanoparticles makes the absorption curves exhibit a slightly declined trend from low wavelength to high wavelength. The protective nanoscale environment impeded photodegradation reactions as found in fatigue investigations.

A diarylethene (1,2-bis(2-methyl-1-benzo-thiophene-3-yl) perfluorocyclopentene) and a matched fluorescent dye (perylenedicarboxylic acid bis(2-methylpropyl) ester) were encapsulated in cross-linked polymeric matrix via a modified miniemulsion polymerization process and a seeded polymerization technique [41]. The dyes were completely co-dissolved in solution of methyl methacrylate, styrene and $\mathrm{N}$-vinylcarbazole comonomers, and glycol dimethacrylate cross-linker. Subsequently, an emulsion of 2-hydroxyethyl methacrylate and glycol dimethacrylate cross-linker was added dropwise into the seeded system, in order to generate an outer crosslinked shell as a passivation layer against light, oxygen degradation and against molecular migration of each component, also as a hydroxyl containing layer for enhancing biocompatibility and storage stability in aqueous dispersion of the nanohybrids. The new type of nanoparticles with average size less than $60 \mathrm{~nm}$ showed excellent fluorescent switching capability as well as improved photo-thermal stability both dispersed in water or in a polymer film.

A nitrobenzoxadiazolyl-based NBD fluorescent dye and a SP (1'-( $\beta$-carboxyethyl)-3',3'-dimethyl-6nitrospiro(indoline-2',2-[2H-1]benzopyran)) were polymerized with methyl methacrylate monomers [80]. The encapsulation efficiency of the dye was $85-95 \%$, the diameter of nanocapsules was $40-80 \mathrm{~nm}$. The size of particles can be controlled by varying the amount of surfactant and hydrophobe, the monomer concentration in water as well as the sonication time.

\section{Microemulsion polymerization}

Photochromic dye (pyrene) - conducting polymer (polypyrrole) core-shell nanoparticles, with diameters of 10 $\mathrm{nm}$, were fabricated using microemulsion micelles as nanoreactors [21]. Polypyrrole (PPy) chains effectively entrapped the pyrene molecules because of their cross-linked character, through an alpha-beta coupling reaction (Scheme 7). The pure polypyrrole nanoparticles and its doped form with most of the common anions are amorphous, however, the pyrene-embedded polypyrrole nanoparticles exhibited a crystalline diffraction pattern. Polymerization of the pyrrole monomer induced phase separation between the polymer and the pyrene. The more hydrophobic pyrene molecules tended to locate in the hydrophobic interior of the micelle. The enhanced hydrophobicity with an increasing pyrene content facilitated the phase separation. The adsorption state of pyrene was tunable over a wide range with a small amount of pyrene, because of the nanosized reaction site of the micelles and the packing constraint of pyrene crystal. The emission colours of the nanohybrids were controllable from violet to blue by changing the amount of embedded pyrene.

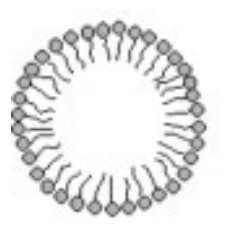

Surfactant micelle in water

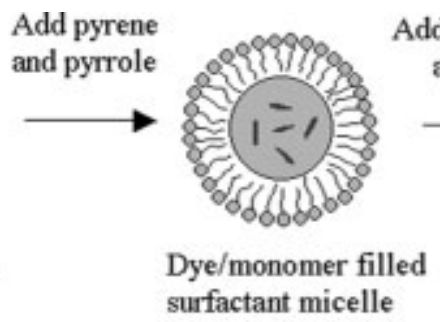
surfactant micelle

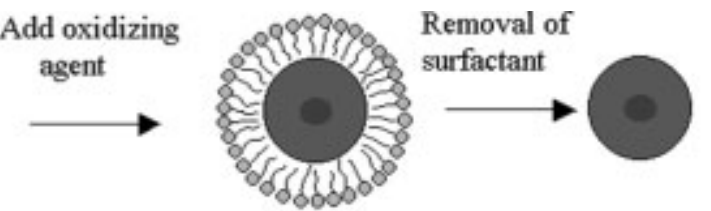

Pyrene-embedded PPy nanoparticle

Scheme 7. Schematic representation of the fabrication of pyrene-embedded PPy nanoparticles (reproduced with permission from [21]). 
The same group [34] synthesized core/shell nanospheres, composed of linear or cross-linked polypyrrole, stepwise by microemulsion polymerization using two oxidants with different chemical oxidation potentials, i.e. copper(II) chloride and iron(III) chloride. The hydrophilic oxidants with different chemical oxidation potentials produced polypyrroles with differing solubility in alcohol. The linear polypyrrole core and cationic surfactants could be removed by one-step solvent etching process simultaneously, and cross-linked nanocapsules were obtained. The core size (19 to $33 \mathrm{~nm})$ and shell thickness $(5.0$ to $12.5 \mathrm{~nm})$ of nanoparticles were tunable by controlling the feeding amount of monomers in each synthetic step. The average diameter of polymer nanocapsules $(32-56 \mathrm{~nm})$ could also be controlled by changing concentration and chain length of the surfactant. Polypyrrole nanocapsules had two mesopores, that is, the inner cavity and the mesochannel in the wall. In addition, polypyrrole hollow nanospheres could be transformed into carbon nanocapsules (ca. $52 \mathrm{~nm}$ diameter) through the carbonization process. The graphitization of carbon capsule wall was facilitated by increasing the carbonization temperature, and the degree of graphitization was higher at the outer part of the wall. The carbonization reactions (elimination and cyclization reactions for graphitization) start at the surface of the polymer nanocapsule. The graphitization is proceeded by the mass-transfer flow from inner shell polymer chains to the outer graphitic materials. The ability to selectively encapsulate and release guest molecules was examined by introducing a photochromic dye (pyrene) solution into the polymer and carbon nanocapsules. Pyrene molecules got into the inner cavity of polymer capsules through mesochannels (ca. $2 \mathrm{~nm}$ ) owing to the hydrophobic interactions. However, benzene solvent removed the dye from the interior of the polymer capsules. The fluorescence of pyrene showed a doughnut shape emission when focusing the Z-axis section in the center of carbon capsule. This means that the concentration of pyrene molecules was higher at the surface of the carbon nanocapsule than that in the inner cavity. The relatively bulky pyrene molecule could not be introduced into the inner cavities because of the absence of mesochannels in the capsule wall. However, pyrene molecules were adsorbed on the outer hydrophobic surface of the carbon capsule in water medium. The doughnut-like emission of pyrene molecules disappeared in benzene medium, where the pyrene molecules were dissolved into the hydrophobic medium.

Hollow nanocapsules with both photoswitchable-fluorescent and reversible-photochromic properties were synthesized via a one-pot non-templating microemulsion copolymerization using methyl methacrylate (MMA) and a SP (1'-(2-Hydroxyethyl)-3',3'-dimethyl-6-nitrospiro(2H-1-benzopyran-2,2'-indoline)) as co-monomers [82]. Size of the nanocapsules ranged from $49 \mathrm{~nm}$ to $93 \mathrm{~nm}$, depending on the amounts of emulsifier and photochromic dye. The SP/MC in the nanocapsules was mostly incorporated inside their wall, with about $17.7 \%$ located on the surface of the wall. The increased photochemical stability of the chromophores compared to the dissolved dye and the unusually strong fluorescence of the $\mathrm{MC}$ form due to UV radiation were attributed to the confinement in the protective nanoscale environment. As generally in polymeric media, the photochemical reactions of the photochromic dye were decelerated due to the rigid environment (Fig. (3)). 

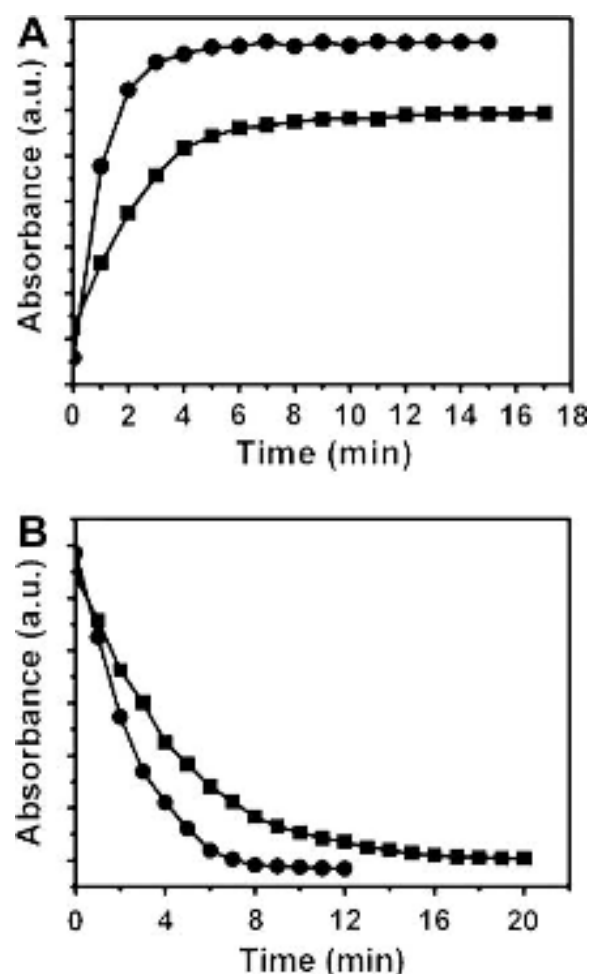

Fig. (3). The intensities based on the absorption maximum from each curve in the UV-visible spectra for the different irradiation time: (A) SP to MC form irradiated on UV (365 nm) and (B) MC to SP form irradiated on visible light (>450 nm) (•:monomer SP molecules; $\mathbf{~ : ~ p o l y ( M M A - S P ) ~ n a n o c a p s u l e s ) . ~ T h e ~ c o n c e n t r a t i o n ~ o f ~ t h e ~}$ $\mathrm{SP}$ in each case is $2.3 \times 10^{-6} \mathrm{M}$ (reproduced with permission from [82]).

\section{Soap-free emulsion polymerization}

Diarylethene (1,2-bis(2,4-dimethyl-5-phenyl-3-thienyl)perfluorocyclopentene) nanocrystal core was prepared by the microwave-assisted nanocrystallization [67]. Obtained nanocrystals were dispersed stably in water without using any surfactant, and then encapsulated by soap-free emulsion polymerization using styrene monomer and divinylbenzene as a cross-linking agent [83]. The crystal structure of core nanocrystals was maintained even after encapsulation. The resulting aqueous dispersion of polystyrene encapsulated diarylethene was purified by centrifugation and redispersion. They had a monodispersed size $(110 \mathrm{~nm})$ and spherical shape with a core size of $76 \mathrm{~nm}$. Lager nanocapsules $(553 \mathrm{~nm})$ had red-shifted absorption peak position, similar to bare diarylethene nanocrystals. That means the encapsulated nanocrystals maintained the size-dependence photochromic properties of core diarylethene. The nanocapsules can be useful components of optically functional devices. 
Table 2 Formulas of photochromes, encapsulating materials and additives as well as size (ranges) of nanoparticles prepared by polymerization techniques.

\begin{tabular}{|c|c|c|c|c|c|}
\hline $\begin{array}{l}\text { Photochrome } \\
\text { type }\end{array}$ & Photochrome & Encapsulating material & Additive(s) & Size (nm) & Ref. \\
\hline Diarylethene & $\begin{array}{l}\text { N-(4-(4-(3,3,4,4,5,5-hexafluoro-2-(2-methyl-5-phenylthiophen-3- } \\
\text { yl)cyclopent-1-enyl)-5-methylthiophen-2-yl)phenyl)acrylamide }\end{array}$ & poly (N-isopropylacrylamide) & $\begin{array}{l}1,1 \text { '-azobis(cyclohexane-1- } \\
\text { carbonitrile) initiator }\end{array}$ & 150 & [74] \\
\hline Diarylethene & 1,2-bis[2-methyl-5-(4-pyridyl)-3-thienyl]cyclopentene & 3,4,5-tris(dodecyloxy)benzoic acid & - & - & {$[75]$} \\
\hline Spiropyran & $\begin{array}{l}\text { 1'-(2-methacryloxyethyl)-3',3'-dimethyl-6-nitro-spiro(2H-1- } \\
\text { benzo-pyran-2,2'-indoline) }\end{array}$ & 4-vinylpyridine, styrene & $\begin{array}{l}\text { Azobisisobutyronitrile } \\
\text { initiator }\end{array}$ & $200-430$ & [76] \\
\hline Spiropyran & $\begin{array}{l}\text { 1'-(2-methacryloxyethyl)-3',3'-dimethyl-6-nitro-spiro(2H-1- } \\
\text { benzo-pyran-2,2'-indoline) }\end{array}$ & $\begin{array}{c}\text { 6-O-methacryloyl-1,2,3,4-di-O- } \\
\text { isopropylidene-D- } \\
\text { galactopyranose), 2-(N,N- } \\
\text { dimethylaminoethyl) methacrylate }\end{array}$ & $\begin{array}{l}\text { Azobisisobutyronitrile } \\
\text { initiator }\end{array}$ & 120 & [77] \\
\hline Spiropyran & $\begin{array}{c}\text { l'-( } \beta \text {-carboxyethyl)-3',3'-dimethyl-6-nitrospiro[indoline-2',2- } \\
\text { chromane] }\end{array}$ & $\begin{array}{l}\text { poly(ethyleneimine), } \\
\text { methyl methacrylate, } \\
\text { ethylene dimethacrylate }\end{array}$ & $\begin{array}{l}\text { nitrobenzoxadiazolyl } \\
\text { fluorescent dye, } \\
\text { tert-butyl hydroperoxide } \\
\text { initiator }\end{array}$ & $80-130$ & {$[78]$} \\
\hline Spiropyran & $\begin{array}{c}\text { 5-(1,3-dihydro-3,3-dimethyl-6-nitrospiro[2H-1-benzopyran-2,2'- } \\
\text { (2H)-indole])ethyl acrylate }\end{array}$ & $N$-isopropylacrylamide, styrene & divinyl benzene cross-linker & $40-400$ & {$[24]$} \\
\hline Spiropyran & $\begin{array}{l}\text { 5-(1,3-dihydro-3,3-dimethyl-6-nitrospiro[2H-1-benzopyran-2,2'- } \\
\text { (2H)-indole])ethyl acrylate }\end{array}$ & $N$-isopropylacrylamide, styrene & $\begin{array}{l}\text { divinyl benzene cross-linker, } \\
\text { perylene diimide fluorescent } \\
\text { dye }\end{array}$ & $50-110$ & [40] \\
\hline $\begin{array}{l}\text { Spiropyran, } \\
\text { diarylethenes }\end{array}$ & $\begin{array}{r}\text { 1',3'-Dihydro-1',3',3'-trimethyl-6-nitrospiro[2H-1-benzopyran- } \\
\text { 2,2'-(2H)-indole], } \\
\text { cis-1,2-dicyano-1,2-bis(2,4,5)-trimethyl(3-thienyl)ethane, } \\
\text { 1,2-bis(2-methylbenzo[b]thiophene-3-yl)hexafluorocyclopentene, } \\
\text { 1,2-dicyano-1,2-bis(2-methylbenzo[b]thiophene-3-yl)ethane, } \\
\text { 1-(6'-acetyl-2'-methylbenzo[b]thiophen-3'-yl)-2-(2''- } \\
\text { methylbenzo-[b]thiophen-3''-yl)hexafluorocyclopentene, } \\
\text { 1-[6'-(methacryloxyethyloxycarbonyl)-2'- } \\
\text { methylbenzo[b]thiophen-3'-yl]-2,(2''methylbenzo[b]-thiophen- } \\
\text { 3''-yl)hexafluorocyclopentene }\end{array}$ & styrene & $\begin{array}{l}\text { azobisisobutyronitrile or } \\
\text { azo-polyethylene glycol } \\
\text { initiator }\end{array}$ & $50-150$ & [79] \\
\hline Spiropyran & $\begin{array}{c}\text { 1-( } \beta \text {-carboxyethyl)-3',3'-dimethyl-6 -nitrospiro (indoline- } \\
\text { 2',2[2H-1] benzopyran) }\end{array}$ & $\begin{array}{l}\text { methyl methacrylate, } 2- \\
\text { hydroxyethyl methacrylate }\end{array}$ & - & $30-60$ & [81] \\
\hline Diarylethene & 1,2-bis(2-methyl-1-benzo-thiophene-3-yl) perfluorocyclopentene & $\begin{array}{l}\text { methyl methacrylate, styrene, } \\
\text { N-vinylcarbazole, } \\
\text { 2-hydroxyethyl methacrylate }\end{array}$ & $\begin{array}{l}\text { perylenedicarboxylic acid } \\
\text { bis(2-methylpropyl) ester } \\
\text { fluorescent dye, glycol } \\
\text { dimethacrylate cross-linker }\end{array}$ & 60 & [41] \\
\hline
\end{tabular}




\begin{tabular}{|c|c|c|c|c|c|}
\hline Spiropyran & $\begin{array}{c}\text { 1'-( } \beta \text {-carboxyethyl)-3',3'-dimethyl-6-nitrospiro(indoline-2',2- } \\
\text { [2H-1]benzopyran) }\end{array}$ & methyl methacrylate & $\begin{array}{l}\text { nitrobenzoxadiazolyl } \\
\text { fluorescent dye }\end{array}$ & $40-80$ & {$[80]$} \\
\hline Pyrene & pyrene & polypyrrole & - & 10 & {$[21]$} \\
\hline Pyrene & pyrene & polypyrrole & $\begin{array}{l}\text { copper(II) chloride, } \\
\text { iron(III) chloride oxidants }\end{array}$ & $32-56$ & [34] \\
\hline Spiropyran & $\begin{array}{l}\text { 1'-(2-Hydroxyethyl)-3',3'-dimethyl-6-nitrospiro(2H-1- } \\
\text { benzopyran-2,2'-indoline) }\end{array}$ & methyl methacrylate & - & $49-93$ & {$[82]$} \\
\hline Diarylethene & 1,2-bis(2,4-dimethyl-5-phenyl-3-thienyl)perfluorocyclopentene & styrene & divinyl benzene cross-linker & 110 & [83] \\
\hline
\end{tabular}




\subsection{Doping \\ Polymer nanoparticles}

Polymer covalently functionalized with photochromic dyes system offers a controlled structure with known photochrome location and concentration but has the disadvantage that a new synthesis must be developed for different polymer or photochromic dye [36]. This drawback can be exceeded by using doped dye-polymer systems. Doped polymer films represent the simplest such system, although often suffer from heterogeneity owing to phase separation. Doped polymer nanoparticles offer a well-defined system without complicated synthesis. The hydrophobicity of the dopants ensures that they are incorporated into the nanoparticles and not partitioning between nanoparticles and aqueous solution.

Homopolymer of poly[2-methoxy-5-(2-ethylhexyloxy)-1,4-phenylenevinylene] (MEH-PPV) or a polyfluorenephenylenevinylene copolymer (PFPV) was doped with a diarylethene (1,2-bis(2,4-dimethyl-5-phenyl-3-thienyl)3,3,4,4,5,5-hexafluoro-1-cyclopentene) [37]. Conjugated polymer nanoparticles had a number-weighted diameter smaller than $11 \mathrm{~nm}$, and they exhibited thermally stable photochromism. Doped MEH-PPV nanoparticles showed successful photomodulation; as a contrary, doped PFPV underwent substantial, irreversible photobleaching upon UV irradiation. Lower energy UV irradiation can be used with many photochromes and caused less photobleaching in doped PFPV nanoparticles, although it did not yield sufficient photoconversion. Another alternative is two-photon irradiation, which replaces a single photon of UV irradiation with two near-IR photons, and is a suitable photomodulator under biological imaging conditions. Harbron and co-workers [36] synthesized similar conjugated nanoparticles, but these contained a SO dye (9'-methoxy-1,3,3trimethylspiro(indoline-2,3'-[3H]-naphth[2,1-b][1,4]oxazine)) [36]. The vast majority of nanoparticles fell in the 5-13 nm range. Both the kinetics of the thermal MC-to-SO conversion and the MC absorption spectrum are sensitive to the dye environment. Two important factors affect the photochromic conversion in the polymer matrix. One of them is the decolouration rate which is slower in rigid matrices than in more flexible systems. The second factor that can have influence on photochromic behaviour is the free volume of the matrix needed for transformation [23]. If the free volume is insufficient, it can decelerate or inhibit the photochromic structure change [36]. The kinetics of the thermal dye reversion in the nanoparticles were of first order and nearly as fast as in an organic solvent. It was hypothesized that those dyes that undergo SO-MC conversion are adhered to solution-exposed MEH-PPV segments within the nanoparticles or to the particle surface and thus had ample free volume for the photochromic conversion. The small size of the nanoparticles increased the likelihood that dyes were in solution-exposed environments.

Photoswitchable poly[9,9-dioctylfluorenyl-2,7-diyl]-co-(1,4-benzo- $\{2,1$ ',3\}-thiadiazole)] dots (54 nm) doped with 1,2-bis(2,4-dimethl-5-phenyl-3-thienyl)-3,3,4,4,5,5-hexafluoro-1-cyclopentene in aqueous solution were synthesized by using a modified precipitation method, and hydrophilic polystyrene graft ethylene oxide functionalized with carboxylic end group (PEG-COOH) were attached to their surface in order to make biocompatible layer, which minimize the non-specific adsorption [63]

Poly(methyl methacrylate) (PMMA) and ethyl cellulose nanocapsules, respectively containing a SO (5-chloro1,3-dihydro-1,3,3-trimethylspiro[2H-indole-2,3'-(3H)naphth[2,1-b](1,4)oxazine]) were prepared by an emulsion - solvent evaporation method [84]. Both encapsulating polymers were suitable for the preparation of nanoparticles in a wide concentration range $(0-30 \% \mathrm{~m} / \mathrm{m}$ dye content). The varying dye concentration did not significantly influence the size of the nanocapsules, which was $250 \mathrm{~nm}$ and $220 \mathrm{~nm}$ for poly(methyl methacrylate) and ethyl cellulose, respectively. Furthermore, the UV-vis absorbance of the dye increased linearly with its concentration in both polymers; that is, the dye did not aggregate in the nanocapsules even in such a wide concentration range [85] (Fig. (4)). The UV-induced coloured MC form ring-closed to the colourless SO form much quicker in an organic solvent than in the nanocapsules. SO in organic solvent has first order decolouration kinetics; hence, its decolouration curve can be characterized with a single lifetime; on the contrary, the bleaching curves of dye in nanocapsules could be fitted properly by using at least two exponential decay equation. Photochemical reactions resulting in fatigue of the coloured form were much slower in the nanocapsules. In a very recent work [86] we applied Tinuvin 144 hindered amine light stabilizer to further improve the fatigue resistance of SO photochromic dye in nanocapsules. Its half-life was elongated by factors of 1.5 and 4.2 in poly(methyl methacrylate) and ethyl cellulose nanocomposites, respectively, containing the light stabilizers related to the corresponding nanocapsules without Tinuvin 144. Nanoparticles were found to keep their photochromic properties in the high temperature screen-printing process [87], and they did not influence the physical properties of printing paste. $0.045 \% w / w$ SO content related to the paste mass provided sufficient colouration, while its doubling did not further the colour development. The incorporation of Tinuvin 144 hindered amine light stabilizer slightly increased the colouration of printed fabric. 

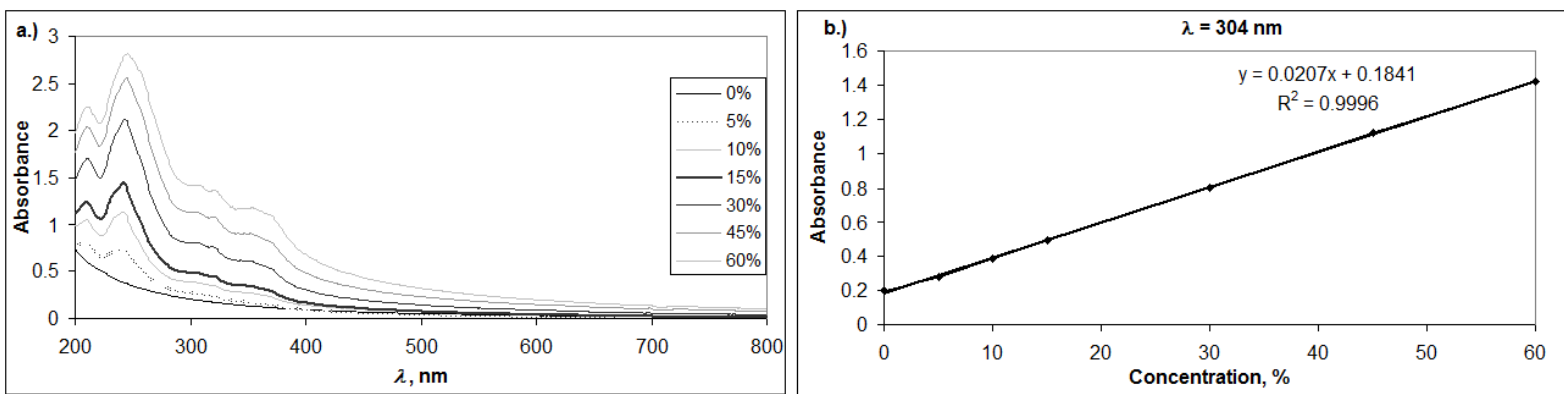

Fig. (4). UV-Vis absorption spectra of spirooxazine in suspensions of ethyl cellulose nanocapsules. Successive spectra were taken after diluting the suspensions of nanocapsules (1\% w/v nanoparticle concentration) containing 0-60\% w/w SO to 1:200 (a.); absorption data measured at $304 \mathrm{~nm}$ in ethyl cellulose-spirooxazine nanocapsule suspensions after 1:200 dilution of the originally $1 \% w / v$ nanoparticle dispersion with $0-60 \% w / w$ SO (b.) (reproduced with permission from [85]).

A family of fluorophore-photochrome dyads, which are able to switch from a non-fluorescent to a fluorescent state, was designed. These compounds fuse $2 \mathrm{H}, 3 \mathrm{H}$-indole and benzooxazine heterocycles within a single covalent skeleton. One member of the developed group was doped into macromolecules that has hydrophilic poly(ethylene glycol) chains and hydrophobic decyl arms appended to a common poly(methacrylate) backbone providing a relatively nonpolar environment (average size: $14 \mathrm{~nm}$ ) [88].

\section{Gels, organogels}

A special class of organic nanocarriers of photochromic dyes involves polymer gels that can exhibit volume phase transition between their swollen- and collapsed state. Above a certain temperature the network shrinks. The temperature at which we can observe network shrinking, a drastic change in volume, is the LCST. Poly(Nisopropylacrylamide) (PNIPA) hydrogels synthesized by radical co-polymerization with photochromic dyes are promising polymers $[38,89]$, because they undergo an abrupt volume change at LCST. Poly(Nisopropylacrylamide) copolymer containing spironaphthoxazine (9'-hydroxy-1,3,3-trimethylspiro[indoline2,3'$[3 \mathrm{H}]$ naphtha[2,1-b][1,4]oxazine]) had excellent photochromic properties and defined thermo-reversible properties in a hydrogel system at LCST [89]. This system constituted a multi-mode complete reversible switch by light, thermal stimuli, base and proton. The addition of equivalent proton produced the protonated PNIPAMC form leading to a new peak at around $520 \mathrm{~nm}$ (pink colour). After visible light irradiation the original absorption spectrum reverted to the initial state of PNIPA-SO. Interestingly, upon addition of equivalent $\mathrm{OH}^{-}$ into the solution previously titrated with proton, the pink solution became blue in colour. When a water solution of PNIPA-SO was heated above the LCST value, the PNIPA-SO converted from the solution state to hydrogel state. After cooling to room temperature, the PNIPA-SO could be recovered in the solution state, the whole process was reversible and could be repeated more than 10 times.

Matsubara et al. [38] developed a co-polymeric porous gel including N-isopropylacryl amide and an azobenzene (4-acryloylaminoazobenzene) photochromic molecule to control gel swelling by light. Spherical silica particles with diameters of $220 \mathrm{~nm}$ and $280 \mathrm{~nm}$ were applied as a template for porous gel preparation. The polymer gel underwent rapid two-state switching between two colours via the trans-cis photoisomerization of the azobenzene (Scheme 3). Azobenzene is mainly in the trans configuration; it has no dipole moment at room termperature in the dark. Irradiation with UV light leads to the production of a cis-isomer with a dipole moment. The back reaction to the trans form occurs upon irradiation with visible light. The change in the dipole moment of the azobenzene group attached to the polymer network influences the free energy of the mixing process between the polymer network and water molecules. Hence, the network expansion of the gel in water can be controlled reversibily and independently by employing thermal and optical stimuli. The major monomer, Nisopropylacrylamide changes its hydrophilicity in response to temperature, whereas 4-acryloylaminoazobenzene undergoes a change in the dipole moment upon the photoisomerization of the azobenzene group. The colour of the porous gel could be rapidly tuned between two states by using photostimuli at a controlled temperature.

Trimethoxymethylsilane co-condensed with trimethoxy(chlorobenzyl)silane formulated highly cross-linked, monodisperse, spherical microgels of about $10 \mathrm{~nm}$ radius for diffusion studies [90]. Therefore, the photochromic dye ortho-nitrostilbene and the fluorophores rhodamine B, coumarin 343, and pyrene, respectively, were covalently bound to the chlorobenzyl functionalized cores inside the polysiloxane shell. For this application, it is essential not to influence the diffusion behaviour by the coupled chromophores. The dye content of the labelled gels decreased with increasing thickness of the protective shell and with a higher polarity of the used chromophores. The fluorescence intensity of the dye-labeled spheres was also influenced by the size of the protective shell, which was explained by differences in mobility of the labels (caging effects) and, at high dye concentration (thinner shell), by reabsorption. 
A donor-acceptor system was constructed by doping N,N'-bis(2,6-diisopropylphenyl)-1,6,7,12-tetraphenoxyperylene-3,4:9,10 acid diimide fluorescent dye and a diarylethene derivative, 1,2-bis(2-methyl-6-nitro-1benzothiophen-3-yl)- perfluorocyclopentene in an optically transparent organogel of tetraethyl orthosilicate (TEOS) prepared by using pregnane steroid organogelator [91].

In another approach UV light-triggered self-assembly of SP-functionalized dendron was introduced into spherical nano-/microparticles [39]. The particle size increased from $500 \mathrm{~nm}$ to $5 \mu \mathrm{m}$ after $120 \mathrm{~s}$ UV light irradiation. By manipulating the cooling process, different self-assembled, SP-functionalized dendron structures were synthesized: spherical nano-/microparticles or 3D interconnected fiber-network within an organogel. Multivalent $\pi-\pi$ interactions of the dendrons was the driving force for the gelation. The UV light irradiation did not destroy the gel phase, and gel-gel transition was realized. The gel exhibited relatively strong red fluorescence, which could be reversibly switched by alternating UV and visible light irradiation. When the concentration was increased, the fluorescence spectrum was red-shifted, which indicated the formation of MC aggregates due to the solvophobic effect. The aggreagation of MC forms restricted the conformational flexibility, which minimized non-radiative relaxation through internal motions of the excited molecules, and the dendron functioned as protective shell for the MC aggregates. As a result the MC form could be isolated from nonradiative decay pathways in solvents. The self-assembly property of dendron minimizes the contact among apolar solvent molecules and polar MC groups, thus lowering the energy of the system. The formed MC particles cannot be totally disassembled by visible light irradiation. The disassembling was complete after heating to $80^{\circ} \mathrm{C}$ for $1 \mathrm{~min}$. New MC aggregates have potential applications in fluorescence imaging, particularly in biological systems. 
Table 3 Formulas of photochromes, encapsulating materials and additives as well as size (ranges) of nanoparticles prepared by doping.

\begin{tabular}{|c|c|c|c|c|c|}
\hline $\begin{array}{l}\text { Photochrome } \\
\text { type }\end{array}$ & Photochrome & Encapsulating material & Additive(s) & Size (nm) & Ref. \\
\hline Diarylethene & $\begin{array}{l}\text { 1,2-bis(2,4-dimethyl-5-phenyl-3-thienyl)-3,3,4,4,5,5- } \\
\text { hexafluoro-1-cyclopentene }\end{array}$ & $\begin{array}{c}\text { poly[2-methoxy-5-(2- } \\
\text { ethylhexyloxy)-1,4- } \\
\text { phenylenevinylene], } \\
\text { polyfluorene-phenylenevinylene }\end{array}$ & - & 150 & {$[37]$} \\
\hline Spirooxazine & $\begin{array}{c}\text { 9'-methoxy-1,3,3-trimethylspiro(indoline-2,3'-[3H]- } \\
\text { naphth[2,1-b][1,4]oxazine) }\end{array}$ & $\begin{array}{c}\text { poly[2-methoxy-5-(2- } \\
\text { ethylhexyloxy)-1,4- } \\
\text { phenylenevinylene] }\end{array}$ & - & $5-13$ & {$[36]$} \\
\hline Diarylethene & $\begin{array}{l}\text { 1,2-bis(2,4-dimethl-5-phenyl-3-thienyl)-3,3,4,4,5,5- } \\
\text { hexafluoro-1-cyclopentene }\end{array}$ & $\begin{array}{c}\text { poly[9,9-dioctylfluorenyl-2,7-diyl]- } \\
\text { co-(1,4-benzo- }\{2,1 \text { ', } 3\} \text {-thiadiazole })] \\
\text { polystyrene graft ethylene oxide } \\
\text { functionalized with carboxylic end } \\
\text { group }\end{array}$ & - & 54 & {$[36]$} \\
\hline Spirooxazine & $\begin{array}{l}\text { 5-chloro-1,3-dihydro-1,3,3-trimethylspiro[2H-indole-2,3'- } \\
\text { (3H)naphth[2,1- } b](1,4) \text { oxazine }]\end{array}$ & $\begin{array}{c}\text { ethyl cellulose, } \\
\text { poly(methyl methacrylate) }\end{array}$ & - & 220,250 & {$[84]$} \\
\hline Oxazine & 2H,3H-indole-benzooxazine & $\begin{array}{l}\text { poly(ethylene glycol)-decyl- } \\
\text { poly(methacrylate) copolymer }\end{array}$ & - & 14 & {$[88]$} \\
\hline Spirooxazine & $\begin{array}{c}\text { 9'-hydroxy-1,3,3-trimethylspiro[indoline2,3'- } \\
[3 \mathrm{H}] \text { naphtha[2,1-b][1,4] oxazine }]\end{array}$ & poly(N-isopropylacrylamide) & - & & [89] \\
\hline Azobenzene & 4-acryloylaminoazobenzene & poly(N-isopropylacrylamide) & - & 220,280 & {$[38]$} \\
\hline Diarylethene & ortho-nitrostilbene & $\begin{array}{l}\text { trimethoxymethylsilane, } \\
\text { trimethoxy(chlorobenzyl)silane }\end{array}$ & $\begin{array}{c}\text { rhodamine B, } \\
\text { coumarin } 343, \\
\text { pyrene fluorophores }\end{array}$ & 10 & {$[90]$} \\
\hline Diarylethene & $\begin{array}{l}\text { 1,2-bis(2-methyl-6-nitro-1-benzothiophen-3-yl)- } \\
\text { perfluorocyclopentene }\end{array}$ & tetraethyl orthosilicate & $\begin{array}{l}\text { N,N'-bis(2,6- } \\
\text { diisopropylphenyl)- } \\
\text { 1,6,7,12-tetraphenoxy- } \\
\text { perylene-3,4:9,10 acid } \\
\text { diimide fluorophore }\end{array}$ & $200-300$ & [91] \\
\hline Spiropyran & $*$ & dendron & - & $500-5000$ & [39] \\
\hline
\end{tabular}




\section{FLUORESCENCE IN CONNECTION WITH PHOTOCHROMISM}

A photochromic conversion followed by a fluorescence change can be applied to various applications in which the reversible photochromic change provides a convenient light-activated method of converting a fluorescent dye to its dark state. Fluorescence detection can be used in non-destructive recording and detection [10,71,91] and bio-imaging $[24,78,80,32,63,88]$, because it requires a much lower power light source than absorption detection. A candidate molecule for a non-destructive readout should possess the ability to turn fluorescence "on" or "off" by photostimulation, while the excitation should not induce ring opening or ring closure of the photochrome. Holographic optical data storage is a unique process for achieving high-density data storage in three dimensions. For biological applications, fluorescence switching should be reversible and high contrast in order to selectively highlight cells, organelles, or proteins [24]. Fluorescence labelling of biomacromolecules and cells has become one of the major tools to study structural organization and intra-/intermolecular processes within biological systems $[32,40,63]$.

The photoinduced activation of an energy transfer process within a fluorophore-photochrome dyad requires the absorbance of the photochrome with its drastical photochemical transformations in the range of wavelengths where the fluorophore emits, and the distance between the fluorophore and photochrome is within the Förster radius (generally 1-10 nm) [78]. The magnitude of this change should be sufficient to ensure that only one of the two interconvertible states of the photochrome can accept the excitation energy of the fluorophore. The energy transfer process issues in the effective quenching of the excited state of the fluorophore with the concomitant suppression of its fluorescence. The spectral overlap between the donor fluorescence and acceptor absorbance spectra is the main contributor to the energy transfer rate [36]. The overlap is quantified by the spectral overlap integral, which depends on the fluorescence intensity of the donor and the extinction coefficient of the acceptor. The Förster radius, at which half of the donor chromophores decay via the energy transfer pathway, is proportional to the spectral overlap integral.

Fluorescent nanoparticles can be prepared by incorporating photochromic dyes that are fluorescent in one of their states, into various nanoparticles by entrapment, or self-assembly strategies [81,24,40,41]. Alternatively, fluorescent components are encapsulated together with photochromic dyes within the same macromolecular construct for fluorescence modulation [41,78,80]. A fluorescent component can be attached to a photochromic switch and then the forming fluorophore-photochrome dyad can be appended to a polymer backbone [92]. In these methods the photochrome acts as a switch for fluorescence quenching: it has no effect on fluorescence intensity in its UV absorbing form but becomes an efficient fluorescence quencher when switched to its visibleabsorbing form. The quenching mechanism may be Förster (fluorescence) resonance energy transfer (FRET), photoinduced electron transfer (PET), or a combination of these mechanisms [37].

Even though many organic chromophores and polymers emit strong fluorescence in dilute solutions, they usually show a reduction in fluorescent efficiency in the solid state because of "concentration quenching", which limits their applicability in fluorescent biological labels, sensors, and light-emitting diodes [75]. To solve the "concentration quenching" problem, unconventional fluorescent systems showing aggregation-induced enhanced emission can be improved. The encapsulation of fluorophores into particles allows integrating multiple fluorophores within a single particle [82]. This not only significantly increases particle brightness, but also avoids the photoinstability caused by the interactions between the fluorophore molecules. Moreover, dual-colour fluorescent particles, especially that can be reversibly photoswitched, can distinguish false positive signals generated by other fluorescent biomolecules. The nanoparticulate environment presents possibilities for the fluorescence modulation of hydrophobic fluorophores in aqueous media [24,78]. Solubilizing the hydrophobic fluorescent dyes, and involving them in hydrophobic medium inside amphiphilic nanoparticles, helps to retain the high fluorescence emission intensity of the dye, and also prevents the unfavorable effects of dye-water interactions. The nanometer size of the particles not only minimizes physical perturbation in biological substances, but also confines a considerable number of the fluorescent dye molecules (donor) and photochromes (acceptor) within the Förster radius. Thus the fluorescence of the former can be photoreversibly modulated by the latter through energy transfer.

Fluorescence techniques are a leading methodology in many biological diagnosis, imaging, and detection applications, primarily because of their versatility, selectivity in highlighting cells, organelles, or proteins and ease of use [78]. Particle-based fluorescent materials are a new application form of the fluorescent technique in biological and optical systems. They have some advantages over conventional fluorescent dyes in many applications, particularly in biotechnology, such as genetic detection, bioimaging, cell labeling and sensing [80]. The main advantage of the fluorescence is the possibility of detecting it at the single molecule level. Fluorescent nanoparticles exhibit high brightness, improved photostability, versatility, biocompatibility and high sensitivity. Ultrahigh-resolution microscopy techniques that can perform much better than diffraction-limited spot sizes are based on emission intensity modulation induced by a light signal (photochromic moiety) [37]. These techniques use temporal switching of fluorophore intensity to achieve ultrahigh resolution: a given fluorophore can be localized with high precision when neighboring fluorophores are switched to a dark or "off" state at the time of imaging. 


\section{Fluorescence of a photochrome}

A transparent colloidal aqueous suspension of microcrystalline powder suspension of diarylethene was competitively photochromic and fluorescent [64]. Irradiating the opened form with UV, the fluorescence of the colloidal suspension decreased and showed a bathochromic shift. The emission was recovered upon visible irradiation. Red-shift and decrease of the nanoparticles fluorescence at the photostationary (closed) form were observed and explained by three factors: radiative energy transfer, non-radiative energy transfer and lower emitting properties compared to opened form. The evolution of the fluorescence ratio can be followed in photochromic systems where the photoisomers emit in different wavelength ranges.

Reprecipitated MC nanoparticles displayed 240 times enhanced fluorescent emission intensity, which was attributed to the combined effects of deactivation of nonradiation process and enhancement of energy transfer, both of which were the result of the much more densely packed molecules exerted by aggregation [69].

Self-assembled dithienylethene with 3,4,5-tris(dodecyloxy)benzoic acid enhanced and red-shifted the fluorescence of the nanoparticles due to [75] hydrogen bond formation between pyridine and carboxylic acid groups, thus displaying an excellent solid fluorescent switch.

Zhu et al. [24] reported the incorporation of photochromic SP dye into polymer nanoparticles to generate optically addressable fluorescent systems. By confining the SP dye into hydrophobic cavities of the nanoparticles, the MC form of the encapsulated dyes became highly fluorescent and its photostability was substantially improved. They also integrated photoswitchable SP dyes with fluorescent perylene diimide into the hydrophobic core of hydrophilic polymer nanoparticles to generate optically addressable two-colour fluorescent systems that exhibit high photoluminescence and superior resistance to photobleaching [40]. Su and co-workers prepared photochromic SP nanoparticles by miniemulsion polymerization that exhibited on/off fluorescence switching properties upon UV-visible irradiations [81]. However, the mechanism on the enhancement of the fluorescence intensity remains unclear. Nanoparticles containing a SP exhibited a strong fluorescence at $650 \mathrm{~nm}$ [81]. The optical switching of fluorescence could be repeated numerous times without any apparent "fatigue" effects.

The rigid, hydrophobic environment of the nanoparticles can restrict nonradiative decay pathways such that the normally non-fluorescent MC becomes highly fluorescent in a hydrophobic core [24]. It is presumed that once SP molecules are incorporated into a rigid substrate, the rotation of the carbon-carbon bonds of the MC is restricted, keeping the molecule at a conformation with high fluorescence quantum yield [82]. The fluorophores confined within the hydrophobic cavities with protective shells are isolated from non-radiative decay pathways or electron-transfer pathways generated by collisions with solution components [24]. Additionally, the high quantum yield can be the result of restricted conformational flexibility, which may minimize non-radiative relaxation through internal motions of the excited molecules. Forward and backward fluorescence switching of the photochromic nanoparticles had essentially the same rates. Unlike photoswitching of dye molecules in solution or on the surface of nanocrystals, the fluorescence switching of the photochromic nanoparticles was rate-limited by polymer dynamics.

MC form of a SP in polymerized vesicle emitted fluorescence at $620 \mathrm{~nm}$, the fluorescence of vesicle dispersion was 1.5 times of that of polymer solution, have more excellent reversibility, and stability than that of its polymer solution [76].

Substrate containing polypyrrole-pyrene nanoparticles could be utilized as a good hole-transporting layer owing to the conducting ability of polypyrrole, and also as an emitting layer due to the electroluminescence properties of pyrene nanoparticles [21]. The amount of pyrene required to modulate the photoluminescence from monomer emission to excimer fluorescence was reduced by an order of magnitude compared with that in a pure pyrene system. The emission colour could be tuned by introducing other organic dyes, such as rhodamine B or fluorescein.

The ideal photochromic dopant for conjugated polymer nanoparticles designed for fluorescent photomodulation cannot quench the host polymer in one form, while it is a very efficient quencher in its other form, and is responsive to irradiation wavelengths that do not affect the host polymer [36]. Conjugated polymer nanoparticles prepared from the homopolymer poly[2-methoxy-5-(2-ethylhexyloxy)-1,4-phenylenevinylene] (MEH-PPV) doped with a photochromic diarylethene dye exhibited efficient fluorescence photomodulation that was thermally irreversible [37]. In their UV absorbing open form, the diarylethenes have no effect on the fluorescence properties. UV irradiation converts the dye to its visible-absorbing closed form, which is an efficient fluorescence quencher via a fluorescence resonance energy transfer mechanism. "On" and "off" fluorescence intensity levels are maintained until the photochrome is switched by irradiation. MEH-PPV doped nanoparticles exhibited reversible quenching and recovery. The same conjugated polymer, doped by a SO, demonstrated identical fluorescence properties to undoped control nanoparticles [36]. The formed nanoparticles showed efficient quenching as a result of very close dye-polymer proximity and not due to simple inner filter effects or other trivial explanations. The doped nanoparticles were designed to undergo efficient FRET to MC dyes. When the dye was in the thermally stable SO form, the fluorescence of the dye-doped nanoparticles was as 
bright as that of undoped nanoparticles. Upon a UV-induced conversion to MC form, the MEH-PPV fluorescence was quenched to less than $10 \%$ of its initial value. The fluorescence modulation could be cycled many times without fatigue, and the degree of quenching was linear with $\mathrm{MC}$ concentration. The fluorescence quenching mechanism in these doped nanoparticles is not known and could be nonradiative energy transfer, radiative energy transfer, electron transfer, or some combination of these mechanisms.

A diarylethene was incorporated into stable, single lamellar liposome, composed of neutral, saturated and positively charged lipids for live cell imaging. The liposomes with the open-ring form did not show fluorescence, while those with the closed-ring isomer gave strong orange-red fluorescence. [32]. Reversibly photoswitchable polymer dots doped with a diarylethene were able to photoswitch fluorescence emission off [63]. Quenching efficiency increased concomitantly with the increase in doping ratio, which confirmed that doped diarylethene regulated the fluorescence on and off. UV light irradiation dramatically decreased the fluorescence intensity due to fluorescence quenching via formation of the closed-ring isomer of diarylethene. Visible light irradiation recovered fluorescence, both in bulk solution and in cell study. These processes were repeatable many times.

A novel fluorophore-photochrome containing $2 \mathrm{H}, 3 \mathrm{H}$-indole and benzooxazine heterocycles within a molecule was doped in poly(ethylene glycol)-decyl-poly(methacrylate) copolymer. Visible irradiation excited the fluorescent fragment of the dye selectively within the ring-open isomer. That is, the irradiation of the sample with an ultraviolet source to open the oxazine ring together with a visible one to excite the photogenerated isomer results in significant fluorescence. It offers the opportunity to reconstruct images of polymer nanoparticles with subdiffraction resolution [88].

\section{Co-encapsulation of a photochrome and a fluorophore}

Perylene diimide fluorophore and SP photochrome in the core of polymer nanocapsules exhibited a two-colour fluorescent system with high photoluminescence and superior resistance to photobleaching [40]. When the photoswitchable dye is in its ring-closed (spiro) form, the perylene diimide strongly emits green fluorescence. However, UV-induced ring-opening converts the spiro compound to its open-ring form (MC) whose visible absorption band nearly coincides with the perylene diimide emission bands. Consequently, the perylene emission is strongly quenched by FRET. The MC revert to the spiro form due to thermal ring-closing, and the green fluorescence of the perylene chromophore appears. Neither spiro- nor MC form of the SP (1'-(2methacryloxyethyl)-3',3'-dimethyl-6-nitro-spiro(2H-1-benzo-pyran-2,2'-indoline)) fluoresce in water, although the mero form possesses weak fluorescence in polar organic solvents and within self-assembled films. However, in the hydrophobic cavities of water-soluble nanoparticles, the MC has strong red fluorescence. In summary, FRET converts the green emission of perylene diimide to red emission of MC photochemically. The fluorescent dye is uniformly dispersed within the hydrophobic core of the nanoparticles; their distance falls within the Förster radius. This close proximity of donor and acceptor molecules, coupled with the high degree of spectral overlap between the perylene diimide emission and MC absorption bands, probably causes highly efficient FRET. The efficiency can be modulated by altering the number density of SP dye molecules, i.e., the distance between energy donor and acceptor, within the nanoparticles; thus, for example, in cases where spectral overlaps are not optimal, partial compensation can be achieved by increasing the relative amount of acceptor.

A thermally stable diarylethene (1,2-bis(2-methyl-1-benzo-thiophene-3-yl) perfluorocyclopentene) and a highly hydrophobic fluorescent dye, perylenedicarboxylic acid bis(2-methylpropyl) ester with high fluorescence and superior photostability were co-encapsulated [41], because the emission band of the energy donor overlaps with the absorption band of the acceptor only in its closed-ring form, but not in its open-ring form, which can be an effective device for the photoswitching of the emission by photoinduced energy transfer.

Self-assembled system containing (Z)-2,3-bis(4'-methyl-[1,1'-biphenyl]-4-yl)-acrylonitrile and 2,3-bis(4'(diphenylamino)-[1,1'-biphenyl]- 4-yl)fumaronitrile fluorophorescent dyes and a photochromic diarylethene, 3,3'-(perfluorocyclopent-1-ene-1,2-diyl)bis(2-methyl-5-phenylthiophene) displayed fluorescence tuning by colour-selective quenching due to the different FRET efficiencies from the blue or red fluorophores to the closed-form of photochrome [41]. Dual fluorescence pattering was achieved by applying two different external stimuli, photo or vapor stimuli, to the film. Photostimulated change was reversible and ranged from violet-blue to orange-red, whereas vapor stimulus resulted in irreversible colouration and ranged from violet-blue to greenish-blue.

The amphiphilic core-shell PEI-graft-(MMA-co-SPMA-co-EDMA) nanoparticles not only greatly enhanced the fluorescence emission of the hydrophobic nitrobenzoxadiazolyl (NBD) dye in aqueous media, probably by accommodating the dye molecules in the interface between the hydrophilic shells and the hydrophobic cores, but also modulated the fluorescence of the dye through intraparticle energy transfer (Scheme 8) [78]. Under these conditions, the photochemical transformation of the SP can activate or suppress the transfer of the excitation energy from a fluorophore to a SP moiety [80]. For the dyad or triad systems, the distance between the energy donor and the acceptor can be controlled by inserting a spacer between them. These dyad or triad systems have the well-defined structure needed for effective energy transfer as well as good fluorescence modulation. The 
energy transfer is only possible from NBD to the MC form. Therefore, before ring-opening of the SP moiety, no fluorescence quenching of NBD could be observed, whereas upon UV irradiation, the SP moiety converts into the open-ring MC form and then the energy transfer from NBD to the MC form of SP became efficient. After incorporating a SP and NBD dyes by miniemulsion polymerization using methyl methacrylate monomers, the fluorescence intensity of the forming nanoparticles increased with the decreasing particle size [80]. One reason can be that the light scattering can reduce the actual number of photons of incindent light received by fluorescent dyes and the larger particles can cause stronger scattering. UV light could be applied to reversibly turn on and off the fluorescence of NBD with a slight fatigue effect. NBD derivative were entrapped in HPMAlpGP(PDMAEMA-co-PSPMA) $)_{n}$ micelles, and represented fluorescence through FRET [80]. Slight fluorescence intensity decrease of the MC form was observed after five UV-visible light irradiation cycles.

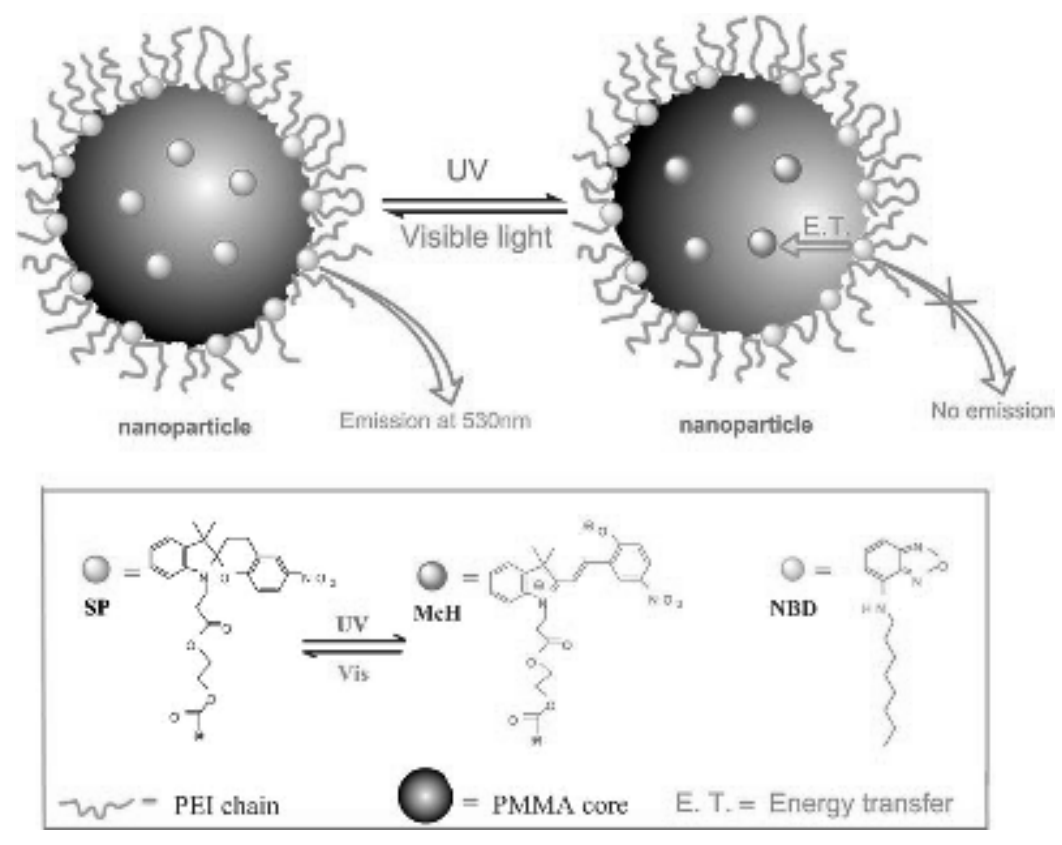

Scheme 8. Photoreversible fluorescence modulation of the NBD-nanoparticle complex (reproduced with permission from [78]).

Nanoparticles consisting of photochromic SO (5-methoxy-1,3,3-trimethyl-9'hydroxyspiroindolinenaphthoxazine), fluorescent 4-(dicyanomethylene)-2-methyl-6-(p-dimethyl-aminostyryl)4H-pyran dye and emissive assistant 1,3-bis(pyrene)propane molecules [70] enhanced the contrast of the fluorescence signal between the on and off state, but also enabled to tune the excitation wavelength for reading the fluorescence. The non-radiative Förster-type energy transfer, in which the dipole-dipole Coulombic resonance interacted between the donor and acceptor, was responsible for the fluorescence quenching. The reversible photochromic modulation of the fluorescence could be observed with little fatigue after several cycles. Applying the same photochrome, fluorophore and additive in poly(methyl methacrylate) film, but not in nanocapsules, only a 7\% quenching of fluorescence was observed. The discrepancy on quenching efficiency was attributed to the fact that doping generated an environment where the photochrome, fluorophore and additive molecules were in close contact, facilitating the occurrence of intermolecular processes.

\section{APPLICATIONS}

Materials containing natural cinnamate groups can be useful for developing photosensitive nanoscaled materials for biomedical and environmental applications [72]. A diarylethene and matched fluorescent dye encapsulated in cross-linked polymeric matrix issued in promising application for erasable optical data storage and individually addressable nanoscale devices which may be developed for utilization in biological and sensor technology [41]. Ethyl cellulose nanoparticles containing SO were excellently dispersed in printing paste, and retained their photochromic properties in the high temperature screen-printing process [87]. Furthermore, the small size $(<1$ $\mu \mathrm{m})$ of nanoparticles may also allow their use in inkjet inks, which are particularly sensitive to particle size due to small nozzle orifice.

Poly(N-isopropylacrylamide) gels containing a SO as a multi-mode reversible switch by light, thermal stimuli, as well as base and proton, possesses promising applications in the fields of opto- and electronic smart materials, logic gate, nanomachines, fluorescence sensors and other molecular photonic devices [89]. The practical 
capability of rewritable high-density fluorescence photoimaging on the PVA film loaded with SO containing nanoparticles was investigated by patterned illumination through photomasks [70]. The reversible 'write' and 'erase' modulation processes could be performed with little fatigue after several cycles. For some special applications such as ratiometric measurement, multiplexed bioassays as well as the applications based on FRET, multiple functional groups, such as chromophores, fluorophores, probes and so on, are incorporated into a single particles system. FRET can be used as a powerful spectroscopic tool in both biological and optical fields [80]. This approach is also suitable in biological imaging and labeling, as well as in reversible data storage/erasing. Controlled amount and ratio of dyes ensure nearly quantitative energy transfer.

The transparent colloidal aqueous suspension of microcrystalline powder suspension of diarylethene can be exploited as a potential ratiometric fluorescent photoswitch for example in sensing, since the measured ratio is independent of the concentration of chromophores [64]. The radiative energy transfer between a perylene diimide fluorophore and a diarylethene photochrome could be used for non-destructive readout, and the fluorescence emission modulation in the gel may be an efficient logic operation. This development may be the basis of soft materials with optoelectronic functions, biomedical and biotechnological applications [91]. Multistimulus fluorescence patterning, reversible fluorescence switching, and nondestructive readout of the fluorescence signal were demonstrated in self-assembled system consisted of a diarylethene and two fluorescent dyes [71].

To evaluate the potential of nanoparticles for biological tagging, SP dye in hydrophilic $N$-isopropylacrylamide shell and styrene core have been delivered into living cells and imaged with a liquid nitrogen-cooled charge coupled device [24]. Using liposomes as a delivery vehicle, optically switchable nanoparticles were introduced into human embryonic kidney cells. In the cytosolic media the fluorescence switching was reversible and quantitatively repeatable. Dual-colour nanoparticles of similar composition, additionally containing perylene diimide fluorescent dye, also displayed reversible fluorescence colour switching in the cytoplasmic cell compartment. The nanoparticles could be selectively highlighted with either green or red fluorescence. Relative intensities of the red and green fluorescent components could be controlled by their ratio used during formation by emulsion polymerization. These high-contrast, highly intense, dual-colour systems, could be applied in tracking and labeling components of complex biological systems. Another SP in biocompatible core-shell PEIgraft-(MMA-co-SPMA-co-EDMA) nanoparticles including a fluorescence dye [78] may also find applications in biological areas such as biological diagnosis, imaging, and detection. The amphiphilic core-shell nanoparticles can also be transported into cells by using liposomes as delivery vehicles in order to highlight cells. In addition, for the detection or diagnosis of cancer cells, the nanoparticle complexes, with amine groups on their surfaces, can be readily conjugated through covalent bonds or coulombic interactions with a specific antibody to form bioconjugated nanoparticles. Pang et al. 2012 [32] reported the live cell imaging of turn-on photochromic fluorescent liposomes containing a diarylethene dye. They found that fluorescence signals were localized mainly in the cytoplasm. They developed a new, home-made detection platform based on total internal reflection fluorescence microscopy that enabled high-resolution live cell images in real-time use at the single cell level. In in vitro photoswitchability investigations no obvious fatigue was observed after multiple switch cycles, and the photochromic compound was non-cytotoxic. Study of a NBD derivative in HPMAlpGP(PDMAEMA-coPSPMA $)_{\mathrm{n}}$ micelles revealed that these photoresponsive biocompatible micelles are a good candidate for cell imaging, thus, they may find broad applications in biological areas such as biological diagnosis, imaging, and detection [77]. Photoswitchable poly(fluorene-alt-benzothiadiazole) dots doped with a diarylethene, and containing hydrophilic biocompatible PEG-COOH layer on the surface is able to minimize the non-specific adsorption, furthermore, carboxylic groups provide an excellent platform for further chemical modification, such as cross-linking with e.g. streptavidin [63]. Hence, polymer dots were functionalized with streptavidin using a carbodiimide. Baby hamster kidney (BHK) cell line were stained with streptavidin functionalized polymer dots in order to recognize biotin labelled tubulin. Tubulin is target for various anticancer drugs. It was demonstrated that diarylethene in polymer dots worked as a "toggle switch" that is useful for biological imaging. A novel skeleton of the fluorophore-photochrome containing $2 \mathrm{H}, 3 \mathrm{H}$-indole and benzooxazine heterocycles within a molecule doped in poly(ethylene glycol)-decyl-poly(methacrylate) copolymer could be valuable probe for the convenient super-resolution imaging of biological samples [88].

Anisotropic diarylethene nanoparticles fabricated by laser ablation could be exploited in the fabrication of optoelectronic devices [65]. The fabrication method can be useful in light-controlled processes, e.g. precipitation or extraction. Substrate containing polypyrrole-pyrene nanoparticles could be a new concept of nanohybrids for electronic devices, since conducting polypyrrole provides a good hole-transporting layer, and the electroluminescence properties of pyrene nanoparticles can serve as an emitting layer [21].

Nanoparticle-protected hydrophobic fluorophores are attractive materials for potential applications such as optical data storage and switching and biological fluorescent labelling, and "smart" photoswithcable inks to protect materials against counterfeit [24]. However, hollow particles may posses a number of obvious advantages over the solid particles, which are versatile for many further developments in switching, optical data storage and biological fluorescent labelling [82]. 
As a brief summary, in the last decade forming procedures of organic nanoparticulate photochromes have been developed and improved significantly. However, some efforts have been made to transfer the basic research into application; the main perspective of following research in photochromic nanoparticles resides in their further development for medical, biotechnological or other industrial users. Hence, it is of crucial importance to focus on photochromes with high fatigue resistance and desirable photochromic and potentially fluorescent properties. Thus, it is indispensable to use achievements of novel photochromes.

\section{ACKNOWLEDGEMENTS}

This work was granted by the Hungarian Economic Development Centre (MAG Zrt.), Hungarian Scientific Research Fund (OTKA) and EU FP7 (Marie Curie action) co-funded 'MOBILITY' programme with the reference number of OMFB-00123/210. We also acknowledge the support of the National Development Agency in Hungary (grant TÁMOP-4.2.2/B-10/1-2010-0025).

\section{References}

[1] Crano, J.C.; Guglielmetti, R.J. Organic photochromic and thermochromic compounds. Volume 1, Main photochromic families, Plenum Press: New York, 1999.

[2] Dorion, G.H.; Wiebe, A.F. Photochromism; Focal Press: New York, 1970.

[3] Patra, A.; Metivier, R.; Piard, J.; Nakatani, K. SHG-active molecular nanorods with intermediate photochromic properties compared to solution and bulk solid states. Chem. Commun., 2010, 46, 6385-6387.

[4] Crano, J.C.; Flood, T.; Knowles, D.; Kumar, A.; VanGemert, B. Photochromic compounds: Chemistry and application in ophthalmic lenses. Pure Appl. Chem., 1996, 68, 1395-1398.

[5] Eppig, T.; Speck, A.; Gillner, M.; Nagengast, D.; Lagenbucher, A. Photochromic dynamics of ophthalmic lenses. Appl. Optics, 2012, 51, 133-138.

[6] Sakamoto, R.; Kume, S.; Nishihara, H. Visible-light photochromism of triarylamine- or ferrocene-bound diethynylethenes that switches electronic communication between redox sites and luminescence. Chem.-Eur. J., 2008, 14, 6978-6986.

[7] Hampp, N.; Fischer, T.; Neebe, M. In Optical security and counterfeit deterrence techniques IV, Proceedings of the Society of Photo-Optical Instrumentation Engineers (SPIE), San Jose, Canada, January 23-25, 2002; VanRenesse, R.L. Ed.; SPIE-Int Soc Optical Engineering, Bellingham, USA, 2002, pp. 121-128.

[8] Zhai, X.; Shi, F.; Chen, H.; Zhao, D.; Zhang, D.; Qin, W. Study on NIR optical rewritable film based on dithienylethene and upconversion nanocrystals. J. Nanosci. Nanotechn., 2011, 11, 9693-9696.

[9] Zhou, Z.; Hu, H.; Yang, H; Yi, T.; Huang, K.; Yu, M. ; Li, F.; Huan, C. Up-conversion luminescent switch based on photochromic diarylethene and rare-earth nanophosphors. Chem. Commun., 2008, 4786-4788.

[10] Zhang, C.; Zhou, H.-P.; Liao, L.-Y.; Feng, W.; Sun, W.; Li, Z.-X.; Xu, C.-H.; Fang, C.-J.; Sun, L.-D.; Zhang, Y.-W.; Yan, C.-H. Luminescence modulation of ordered upconversion nanopatterns by a photochromic diarylethene: rewritable optical storage with nondestructive readout. Adv. Mater., 2010, 22, 633-637.

[11] Carling, C.-J.; Boyer, J.-C.; Branda, N.R. Multimodal fluorescence modulation using molecular photoswitches and upconverting nanoparticles. Org. Biomol. Chem., 2012, 10, 6159-6168.

[12] Wu, T.; Tank, H.; Bohne, C.; Branda, N.R. Reporting the release of caged species by a combination of two sequential photoreactions, a molecular switch, and one color of light. Angew. Chem. Int. Ed., 2012, 51, 27412744.

[13] Li, Y.-R.; Zhang, H.-T.; Qi, C.-M.; Guo, X.F. New spiropyran derivatives: ion sensing and information processing at the molecular level. Acta Phys.-Chim. Sin., 2012, 28, 2471-2479.

[14] Lendlein, A.; Jiang, H.Y.; Junger, O.; Langer, R. Light-induced shape-memory polymers. Nature, 2005, $434,879-882$

[15] Willner, I. Photoswitchable biomaterials: En route to optobioelectronic systems. Acc. Chem. Res., 1997, 30, $347-356$

[16] Kawatsuki, N.; Goto, K.; Kawakami, T.; Yamamoto, T. Reversion of alignment direction in the thermally enhanced photoorientation of photo-cross-linkable polymer liquid crystal films. Macromolecules, 2002, 35, 706713.

[17] Zho, X.X.; Chung, H.K.; Lam, A.J.; Lin M.Z. Optical control of protein activity by fluorescent protein domains. Science, 2012, 338, 810-814.

[18] Yun, C.; You, J.; Kim, J.; Huh, J.; Kim, E. Photochromic fluorescence switching from diarylethenes and its applications. J. Photochem. Photobiol. C, 2009, 10, 111-129.

[19] Jeong, J.;Yun, E.; Choi, Y.; Jung, H.Y.; Chung, S.J.; Song, N.W., Chung, B.H. Photoreversible cellular imaging using photochrome-conjugated fullerene silica nanoparticles. Chem. Commun., 2011, 47, 10668-10670.

[20] Zou, Y.; Yi, T., Xiao, S.; Li, F.; Li, C.; Gao, X.; Wu, J.; Yu, M.; Huang, C. Amphiphilic diarylethene as a photoswitchable probe for imaging living cells. J. Am. Chem. Soc., 2008, 130, 15750-15751. 
[21] Jang, J.; Oh, J.H. Facile fabrication of photochromic dye-conducting polymer core-shell nanomaterials and their photoluminescence. Adv. Mater., 2003, 15, 977-980.

[22] Bouas-Laurent, H.; Durr, H. Organic photochromism. Pure Appl. Chem., 2001, 73, 639-665.

[23] Such, G.; Evans, R.A.; Yee, L.H.; Davis, T.P. Factors influencing photochromism of spiro-compounds within polymeric matrices, J. Macromol. Sci. C, 2003, 43, 547-579.

[24] Zhu, M.Q.; Zhu, L.; Han, J.J.; Wu, W.; Hurst, J.K.; Li, A.D.Q. Spiropyran-Based Photochromic Polymer Nanoparticles with Optically Switchable Luminescence. J. Am. Chem. Soc., 2006, 128, 4303-4309.

[25] Chen, B.Z. Molecular structure analysis of photochromic diarylethene. Curr. Org. Chem., 2007, 11, 12591271.

[26] Nakamura, S.; Irie, M. Thermally irreversible photochromic systems - A theoretical study. J. Org. Chem., 1988, 53, 6136-6138.

[27] Irie, M. Diarylethenes for memories and switches. Chem. Rev., 2000, 100, 1685-1716.

[28] Jelly, E.E. Spectral absorption and fluorescence of dyes in the molecular state. Nature, 1936, 138, 10091010.

[29] Matsumoto, M.; Nakazawa, T.; Azumi, R.; Tachibana, H.; Yaman-aka, Y.; Sakai, H.; Abe, M. Lightinduced J-aggregation of merocyanine in Langmuir and Langmuir-Blodgett films. J. Phys Chem. B, 2002, 106, $11487-11491$.

[30] Krongauz, V.A.; Fishman, S.N., Goldburt, E.S. Quasi-crystals. Growth from photochromic spiropyrans on irradiation in a constant electric field. J. Phys. Chem., 1978, 82, 2469-2474.

[31] Straight, S.D.; Liddell, P.A.; Terazono, Y.; Moore, T.A.; Moore, A.L.; Gust, D. All-photonic molecular XOR and NOR logic gates based on photochemical control of fluorescence in a fulgimide-porphyrindithienylethene triad. Adv. Funct. Mater., 2007, 17, 777-785.

[32] Pang, S.-C.; Hyun, H.; Lee, S.; Jang, D.; Lee, M.J.; Kang, S.H. Photoswitchable fluorescent diarylethene in a turn-on mode for live cell imaging. Chem. Commun., 2012, 48, 3745-3747.

[33] Szymanski, C.; Wu, C.F.; Hooper, J.; Salazar, M.A.; Perdomo, A.; Dukes, A.; McNeill, J. Single molecule nanoparticles of the conjugated polymer MEH-PPV, preparation and characterization by near-field scanning optical microscopy. J. Phys. Chem. B, 2005, 109, 8543-8546.

[34] Jang, J.; Oh, J.H.; Li, X.L. A novel synthesis of nanocapsules using identical polymer core/shell nanospheres. J. Mater. Chem., 2004, 14, 2872-2880.

[35] Spangenberg, A.; Metivier, R.; Gonzalez, J.; Nakatani, K.; Yu, P.; Giraud, M.; Leaustic, A.; Guillot, R.; Uwada, T.; Asahi, T. Multiscale approach of photochromism: synthesis and photochromic properties of a diarylethene in solution, in nanoparticles, and in bulk crystals. Adv. Mater., 2009, 21, 309-313.

[36] Harbron, E.J.; Davis, C.M.; Cambell, J.K.; Allred, R.M.; Kovary, M.T.; Economou, N.J. Photochromic dyedoped conjugated polymer nanoparticles: photomodulated emission and nanoenvironmental characterization, $J$. Phys. Chem. C, 2009, 113, 13707-13714.

[37] Davis, C.M.; Childress, E.S.; Harbron, E.J. Ensemble and single-particle fluorescence photomodulation in diarylethene-doped conjugated polymer nanoparticles. J. Phys. Chem. C, 2011, 115, 19065-19073.

[38] Matsubara, K.; Watanabe, M.; Takeoka, Y. A thermally adjustable multicolor photochromic hydrogel. Angew. Chem. Int. Ed., 2007, 46, 1688-1692.

[39] Chen, Q.; Feng, Y.; Zhang, D.; Zhang, G.; Fan, Q.; Sun, S.; Zhu, D. Light-triggered self-assembly of a spiropyran-functionalized dendron into nano-/micrometer-sized particles and photoresponsive organogel with switchable fluorescence. Adv. Funct. Mater., 2010, 20, 36-42.

[40] Zhu, L.; Wu, W.; Zhu, M.-Q.; Han, J.J.; Hurst, J.K.; Li, A.D.Q. Reversibly photoswitchable dual-color fluorescent nanoparticles as new tools for live-cell imaging. J. Am. Chem. Soc., 2007, 129, 3524-3526.

[41] Hu, Z., Zhang, Q., Xue, M., Sheng, Q., Liu, Y.G., Fluorescent photoswitchable nanohybrids based on photochromism. Journal of Physics and Chemistry of Solids, 2008, 69, 206-210.

[42] Okubo, M.; Enomoto, M.; Kojima, N. Reversible photomagnetism in a cobalt layered compound coupled with photochromic diarylethene. Solid State Commun., 2005, 134, 777-782.

[43] Kojima, N.; Okubo, M.; Shimizu, H.; Enomoto, M. Control of magnetism by isomerization of intercalated molecules in organic-inorganic hybrid systems. Coordin. Chem. Rev., 2007, 251, 21-24.

[44] Yamaguchi, H.; Matsuda, K.; Irie, M. Excited-state behavior of a fluorescent and photochromic diarylethene on silver nanoparticles. J. Phys. Chem. C, 2007, 111, 3853-3862.

[45] Hu, J.; Zhang, J.; Liu, J.; Kittredge, K.; Whitesell, J.K.; Fox, M.A. Competitive photochemical reactivity in a self-assembled monolayer on a colloidal gold cluster. J. Am. Chem. Soc., 2001, 123, 1464-1470.

[46] Kudernac, T.; Van der Molen, S.J.; Van Wees, B.J.; Feringa, B.L. Uni- and bi-directional light-induced switching of diarylethenes on gold nanoparticles. Chem. Commun., 2006, 3597-3599.

[47] Perrier, A.; Maurel, F.; Aubard, J. Theoretical study of the electronic and optical properties of photochromic dithienylethene derivatives connected to small gold clusters. J. Phys. Chem. A 2007, 111, 9688-9698.

[48] Shin, K.H.; Shin, E.J. Photoresponsive azobenzene-modified gold nanoparticle. Bull. Korean Chem. Soc., 2008, 29, 1259-1262. 
[49] Nishi, H.; Kobatake, S. Facile preparation of gold nanoparticle with diarylethene polymers by disodium malate and its photoreversible optical properties. Dyes Pigments, 2012, 92, 847-853.

[50] Piech, M.; Bell, N.S. Controlled synthesis of photochromic polymer brushes by atom transfer radical polymerization. Macromolecules, 2006, 39, 915-922.

[51] Foelling, J.; Polyakova, S.; Belov, V.; van Blaaderen, A.; Bossi, M.L.; Hell, S.W. Synthesis and characterization of photoswitchable fluorescent silica nanoparticles. Small, 2008, 4, 134-142.

[52] Lin, T.; Wang, X. Nano related research in fibres and textiles. Int. J. Nanotechnol., 2009, 6(5/6), 579-598.

[53] Mizoshita, N.; Yamanaka, K.; Hiroto, S.; Shinokubo, H., Tani, T., Inagaki, S. Energy and electron transfer from fluorescent mesostructured organosilica framework to guest dyes. Langmuir, 2012, 28, 3987-3994.

[54] Tomasulo, M.; Yildiz, I.; Raymo, F.M. Nanoparticle-induced transition from positive to negative photochromism. Inorg. Chim. Acta, 2007, 360, 938-944.

[55] Zhu, L.; Zhu, M.Q.; Hurst, J.K.; Li, A.D.Q. Light-controlled molecular switches modulate nanocrystal fluorescence. J. Am. Chem. Soc., 2005, 127, 8968-8970.

[56] Zhang, H.; Yi, T.; Li, F.; Delahaye, E.; Yu, P.; Clement, R. Photochromic response of nanoparticles of spiropyran-MnPS3 intercalate: A search for optically bistable nanocomponents. J. Photochem. Photobiol. A, 2007, 186, 173-177.

[57] Zou, Y.; Xiao, S.; Yi, T.; Zhang, H.; Li, F.; Huang, C. J. Phys. Org. Chem., 2007, 20, 975-980.

[58] Klajn, R.; Stoddart, J.F.; Grzybowski, B.A. Nanoparticles functionalised with reversible molecular and supramolecular switches. Chem.Soc.Rev., 2010, 39, 2203-2237.

[59] Ariga, K.; Vinu, A.; Yamauchi, Y.; Ji, Q.; Hill, J.P. Nanoarchitectonics for mesoporous materials. Bull. Chem. Soc. Jpn., 2012, 85, 1-32.

[60] Katsonis, N.; Lubomska, M.; Pollard, M.M.; Feringa, B.L.; Rudolf, P. Synthetic light-activated molecular switches and motors on surfaces. Prog. Surf. Sci., 2007, 82, 407-434.

[61] Paramonov, S.V.; Lokshin, V.; Federova, O.A. Spiropyran, chromene or spirooxazine ligands: Insights into mutual relations between complexing and photochromic properties. J. Photochem. Photobiol. C, 2011, 12, 209236.

[62] Ortica, F. The role of temperature in the photochromic behaviour. Dyes Pigments, 2012, 92, 807-816.

[63] Osakada, Y.; Hanson, L.; Cui, B. Diarylethene doped biocompatible polymer dots for fluorescence switching. Chem. Commun., 2012, 48, 3285-3287.

[64] Piard, J.; Metivier, R.; Giraud, M.; Leaustic, A.; Yu, P.; Nakatani, K. Photoswitching in diarylethene nanoparticles, a trade-off between bulk solid and solution: towards balanced photochromic and fluorescent properties. New J. Chem., 2009, 33, 1420-1426.

[65] Patra, A.; Metivier, R.; Brisset, F.; Nakatani, K. Photochromic one-dimensional nanostructures based on dithienylethene: fabrication by light-induced precipitation and reversible transformation in the nanoparticle state. Chem. Commun., 2012, 48, 2489-2491.

[66] Hadjoudis, E.; Chatziefthimiou, S.D.; Mavridis, I.M. Anils: photochromism by H-transfer. Curr. Org. Chem., 2009, 13, 269-286.

[67] Tagawa, N.; Masuhara, A.; Kasai, H.; Nakanishi, H.; Oikawa, H. Monodispersed and size-controlled diarylethene nanoparticles fabricated by the reprecipitation mehtod. Mol. Cryst. Liq. Cryst., 2010, 520, 245-250.

[68] Sun, F.; Zhang, F.; Zhao, F.; Zhou, X.; Pu, S. Preparation and photochromic properties of diarylethene nanoparticles. Chem. Phys. Lett., 2003, 380, 206-212.

[69] Liu, Y.Y.; Fan, M.G.; Zhang, C.R.; Sheng, X.H.; Yao, J.N. Novel properties of photochromic spirooxazine nanoparticles. Chinese J. Chem., 2007, 25, 1612-1616.

[70] Sheng, X.; Peng, A.; Fu, H.; Liu, Y.; Zhao, Y.; Ma, Y.; Yao, J. Modulation of a fluorescence switch based on photochromic spirooxazine in composite organic nanoparticle. Nanotechnology, 2007, 18, 145707.

[71] Kim, S.; Yoon, S.-J.; Park, S.Y. Highly fluorescent chameleon nanoparticles and polymer films: multicomponent organic systems that combine FRET and photochromic switching. J. Am. Chem. Soc., 2012, 134, 12091-12097.

[72] Shi, D.; Matsusaki, M.; Kaneko, T.; Akashi, M. Photo-cross-linking and cleavage induced reversible size change of bio-based nanoparticles. Macromolecules, 2008, 41, 8167-8172.

[73] Yi, J.; Chen, Z.; Xiang, J.; Zhang, F. Photocontrollable J-aggregation of a diarylethene-phthalocyanine hybrid and its aggregation-stabilized photochromic behavior. Langmuir, 2011, 27, 8061-8066.

[74] Lim, S.J.; Carling, C.J.; Warford, C.C.; Hsiao, D.; Gates, B.D.; Branda, N.R. Multifunctional photo- and thermo-responsive copolymer nanoparticles. Dyes Pigments, 2011, 89, 230-235.

[75] Xiao, S.; Zou, Y.; Wu, J.; Zhou, Y.; Yi, T.; Li, F.; Huang, C. Hydrogen bonding assisted switchable fluorescence in self-assembled complexes containing diarylethene: controllable fluorescent emission in the solid state. J. Mater. Chem., 2007, 17, 2483-2489.

[76] Huang, C.Q.; Wang, Y.; Hong, C.Y.; Pan, C.Y. Spiropyran-Based Polymeric Vesicles: Preparation and Photochromic Properties. Macromol. Rapid Commun. 2011, 32, 1174-1179. 
[77] Wang, Y.; Hong, C.-Y.; Pan, C.-Y. Spiropyran-based hyperbranched star copolymer: synthesis, phototropy, FRET, and bioapplication. Biomacromolecules, 2012, 13, 2585-2593.

[78] Chen, J.; Zeng, F.; Wu, S.; Chen, Q.; Tong, Z. A core-shell nanoparticle approach to photoreversible fluorescence modulation of a hydrophobic dye in aqueous media. Chem. Eur. J., 2008, 14, 4851-4860.

[79] Han, M.; Lee, E.; Kim, E. Preparation and optical properties of polystyrene nanocapsules containing photochromophores. Opt. Mater., 2002, 21, 579-583.

[80] Chen, J.; Zeng, F.; Wu, S.; Su, J.; Tong, Z. Photoreversible fluorescent modulation of nanoparticles via onestep miniemulsion polymerization. Small, 2009, 5, 970-978.

[81] Su, J.; Chen, J.; Zeng, F; Chen, Q.; Wu, S.; Tong, Z. Synthesis and photochromic property of nanoparticles with spiropyran moieties via one-step miniemulsion polymerization. Polym. Bull., 2008, 61, 425-434.

[82] Wu, Y.; Qu, X.; Huang, L.; Qiu, D.; Zhang, C.; Liu, Z.; Yang, Z.; Feng, L. Optically switchable organic hollow nanocapsules. J. Colloid Interf. Sci., 2010, 343, 155-161.

[83] Tagawa, N.; Masuhara, A.; Onodera, T.; Kasai, H.; Oikawa, H. Polystyrene-encapsulated diarylethene nanocrystals by soap-free emulsion polymerization. J. Mater. Chem., 2011, 21, 7892-7894.

[84] Feczkó, T.; Varga, O.; Kovács, M.; Vidóczy, T B. Voncina, Preparation and characterization of photochromic poly(methyl methacrylate) and ethyl cellulose nanocapsules containing a spirooxazine dye, $J$. Photoch. Photobio. A, 2011, 222, 293-298.

[85] Feczkó, T.; Samu, K.; Wenzel, K.; Neral, B.; Voncina, B. Textile screen-printed with photochromic nanoparticles. Proceedings of the $7^{\text {th }}$ Central European Conference, Portoroz, Slovenia, 15-17 September, 2012, Sfiligoj Smole, M.; Voncina, B.; Kurecic, M.; Kreze, T., Eds.; Univeristy of Maribor, Maribor, Slovenia, 2012, pp. 232-240.

[86] Feczkó, T.; Kovács, M.; Voncina, B. Improvement of fatigue resistance of spirooxazine in ethyl cellulose and poly(methyl methacrylate) nanoparticles using a hindered amine light stabilizer, J. Photoch. Photobio. A, 2012, 247, 1-7.

[87] Feczkó, T.; Samu, K.; Wenzel, K.; Neral, B.; Voncina, B. Textile screen-printed with photochromic ethyl cellulose-spirooxazine composite nanoparticles. Color. Technol., 2013, 129, 1-6.

[88] Deniz, E.; Tomasulo, M.; Cusido, J.; Yildiz, I.; Petriella, M.; Bossi, M.L.; Sortino, S.; Raymo, F.M. Photoactivatable fluorophores for super-resolution imaging based on oxazine auxochromes. J. Phys. Chem. C, 2012, 116, 6058-6068.

[89] Wang, S.; Choi, M.S.; Kim, S.H. Multiple switching photochromic poly(N-isopropylacrylamide) with spironaphthoxazine hydrogel. Dyes Pigments, 2008, 78, 8-14.

[90] Graf, C.; Schartl, W.; Fischer, K.; Hugenberg, N. Dye-labeled poly(organosiloxane) microgels with coreshell architecture. Langmuir, 1999, 15, 6170-6180.

[91] Edelsztein, V.C.; Jares-Erijman, E.A.; Muellen, K.; Di Chenna, P.H.; Spagnuolo, C.C. A luminescent steroid-based organogel: ON-OFF photoswitching by dopant interplay and templated synthesis of fluorescent nanoparticles. J. Mater. Chem., 2012, 22, 21857-21861.

[92] Yildiz, I.; Deniz, E.; Raymo, F.M. Fluorescence modulation with photochromic switches in nanostructured constructs. Chem. Soc. Rev., 2009, 38, 1859-1867. 